\title{
Ejes de infraestructura vial y dinámicas urbano-regionales. El caso del corredor Bogotá-Bucaramanga, Colombia $(1950-2005)^{1}$
}

\author{
Road Infrastructure Axes and Urban- \\ Regional Dynamics. Study Case of the \\ Road between Bogotá and Bucaramanga, \\ Colombia (1950-2005)
}

\section{Eixos rodoviários e dinâmicas urbano- regionais. O caso do corredor Bogotá- Bucaramanga, Colombia (1950-2005)}

\author{
María Patricia Rincón Avellaneda ${ }^{2}$ \\ Líder grupo de investigación Arquitectura-Ciudad-Territorio \\ Universidad Nacional de Colombia. Sede Bogotá \\ mprincona@unal.edu.co
}

Recibido: $29 / 09 / 2015$

Aprobado: 06/05/2016

1 Esta investigación fue realizada con el apoyo de la Vice-decanatura de Investigación de la Facultad de Artes de la Universidad Nacional de Colombia. Parte del estudio de caso que se presenta en este artículo pertenece a la ponencia para el Encuentro Nacional de Investigadores ENID-2014, organizado en la Universidad Nacional de Colombia entre el 22 y el 24 de octubre. Un artículo corto relacionado con la ponencia presentada fue aceptado por la ENID para publicar las memorias del evento en la web. http://www.enid.unal.edu.co/2014/documentos/memorias_enid_2014/ Ejes\%20de\%20Conectividad\%20Vial\%20y\%20Din\%C3\%Almicas\%20Urbano\%2oRegionales.pdf

2 Arquitecta, PhD. Urbanismo. 


\title{
Resumen
}

La pregunta central del presente artículo gira en torno a cómo la planificación territorial y el diseño de infraestructuras de transporte influencian y generan condiciones de desequilibrio territorial. Para resolverla, se presenta el estudio de caso del eje vial que une las ciudades de Bogotá D.C., capital de Colombia, y Bucaramanga, capital del departamento de Santander. A través de una serie de indicadores, se revisaron sus dinámicas con el fin de identificar los cambios producidos en el período 1950-2005, durante el cual se pasa de tener solo una vía de comunicación a tener tres. En ese lapso se encontraron señales claras de migración poblacional, decaimiento de la actividad económica, y de flujos de transporte en las poblaciones ubicadas a lo largo de la ruta más antigua, que entra en desuso al momento de aparecer la segunda opción.

Palabras clave: infraestructuras viales; dinámicas urbano-regionales; impacto; territorio; dinámicas económicas.

\begin{abstract}
The main question of present article is focused around how the territorial planning and the design of transportation infrastructure impact and generate conditions of territorial unbalance. To solve this question, the case study of the road axis which connects the cities of Bogotá D.C., capital of Colombia, and Bucaramanga, capital of Santander Department, is presented. Through a series of indicators, their dynamics were reviewed in order to identify changes produced in the period 1950-2005, during which it happens to have only one communication route to have three roads. During that period, clear signals of population migration, decay of the economic activity and traffic flows in the towns located along the ancient road were found. The old road enters into disuse when the second option appears.
\end{abstract}

Keywords: road infrastructure; regional-urban dynamics; impact; territory; economic dynamics.

\section{Resumo}

A pergunta central do presente artigo orienta-se no modo como o planejamento territorial e o desenho de infraestruturas de transporte, influenciam e geram condições de desequilibro territorial. Para resolve-la, apresenta-se um estudo de caso do eixo rodoviário que une as cidades de Bogotá D.C., capital da Colômbia e Bucaramanga, capital do Estado de Santander. Através de uma série de indicadores, se revisaram suas dinâmicas, com o fim de identificar as mudanças produzidas no período 1950-2005, no qual se ampliam as vias de comunicação. Nesse lapso, se encontraram sinais claras de migração populacional, declive da atividade econômica, e fluxos de transporte em localidades situadas ao longo da rota mais antiga, que entra em desuso no momento de surgir a segunda opção.

Palavras-chave: infraestruturas rodoviárias, dinâmicas urbano-regionais; impacto; território; dinâmicas económicas.

Este trabajo está bajo la licencia Creative Commons Attribution 3.0

¿Cómo citar este artículo? / How to quote this article?

Rincón-Avellaneda, Patricia. «Ejes de infraestructura vial y dinámicas urbano-regionales. El caso del corredor Bogotá-Bucaramanga, Colombia (1950-2005)». Sociedad y economía, No. 31 (julio - diciembre 2016): 33-70. 


\section{Introducción}

Desde la perspectiva del ordenamiento territorial, el estudio de las dinámicas urbano-regionales, en adelante DUR, así como de las diferentes realidades asociadas a los fenómenos territoriales, requiere de un marco conceptual que oriente su abordaje. Para ello, consideramos necesario incluir enfoques teóricos presentes no solo en los campos del ordenamiento territorial, la geografía o el urbanismo, sino en las ciencias sociales en su conjunto. No podríamos hablar de la existencia de una teoría única desde la cual haya sido abordada la cuestión territorial, dado que esto se ha hecho desde diversos marcos conceptuales coexistentes históricamente y que han tenido un impacto profundo en las teorías económicas, urbanas, rurales y regionales (Hissong 1996).

Para dar cuenta del enfoque con el cual se abordó esta investigación, recurrimos a un documento de trabajo elaborado desde el grupo de investigación Arquitectura-Ciudad y Territorio, en el que se estudiaron los enfoques del positivismo, el estructuralismo, el materialismo dialéctico y la complejidad (Rincón y Sandoval 2012). A partir de allí, esta investigación propuso desarrollar los siguientes principios propios del enfoque del pensamiento complejo (Morin 1998): entender todo fenómeno como efecto y causa a la vez, dejando de lado la relación causa-efecto unidireccional. Explicar las dinámicas en términos de sus relaciones recíprocas y de su carácter complejo buscando evidenciar la interrelación e influencia de diferentes indicadores. Desarrollar una mirada multiescalar, multidimensional y multitemporal de las DUR, las cuales por ser dinámicas se transforman constantemente.

El objetivo de la investigación fue aportar evidencias de los cambios experimentados en los núcleos de población ubicados a lo largo del eje vial Bogotá-Bucaramanga, sometidos a tensiones en sentidos contrarios: intensificación o decaimiento. La escogencia de ese eje vial se hizo luego de constatar que a lo largo de cinco décadas (1950-2005), la conexión entre estas dos ciudades fue pasando de una sola opción a tres, lo que permitía establecer comparaciones y correlaciones entre los indicadores revisados para las tres rutas.

La hipótesis central plantea que la existencia o no de infraestructuras tiene la capacidad de jalonar cambios, bien sea porque intensifican la actividad en ciertos lugares, o porque la debilitan y que la existencia o no de vías de comunicación, está movida frecuentemente por la lógica económica, es decir, por el interés que cobra cierto bien o producto natural o manufacturado, en determinados momentos de la historia y bajo la lógica de la acumulación del capital. "Es así que vastas concentraciones de fuerza productiva en unos lugares contrastan con regiones vacías" (Espinosa, Rincón y Ramírez 2011).

Metodológicamente fue necesario establecer como área de influencia de cada uno de los tres corredores los municipios conectados directamente por alguno de ellos, incluyendo aquellos ubicados en su borde inmediato. De allí se seleccionó como unidad de análisis el municipio, identificando un universo de 51 municipios atravesados por alguna de las tres rutas. Se documentaron aquellas variables cuyos indicadores permitieran establecer comparaciones de tipo cuantitativo y correlaciones entre ellas. En paralelo se llevó a cabo un recorrido por los municipios de dos de las tres rutas, para reconocer su realidad actual (calidad 
de la vía, tiempos de recorrido, distancias, perfil económico de los municipios, y calidad y frecuencia del servicio de transporte público).

Los indicadores seleccionados se han agrupado en las siguientes variables:

- Variable demográfica: población según municipios y tasas de crecimiento intercensal.

- Variable histórica: año de fundación de los municipios y fases de expansión de la red vial y configuración de las tres rutas.

- Variable geográfica: relieve/topografía a lo largo del trazado de las tres rutas.

- Variable económica: actividad agrícola, flujos de tránsito promedio diario -TPD-, eficiencia de la red.

La existencia de las tres opciones de conexión entre estas dos ciudades, ligada cada una de ellas a una época, una economía y una topografía específicas, permitió identificar las modificaciones ocurridas por efecto de la aparición de cada nueva ruta.

¿Cómo se estudian en otros contextos las relaciones entre ciudades y las DUR? Las investigaciones del grupo Global and World Cities -GaWC- de la Universidad de Loughborough en Inglaterra que tienen como centro de estudio la escala global resultaron de interés, especialmente el trabajo de Taylor (1997) aportó a la necesidad de encontrar explicaciones para entender no solo las redes mundiales de ciudades, sino la jerarquía que se establece entre ellas. Permitió vislumbrar fuentes no convencionales utilizadas por estos investigadores para suplir la carencia de datos sobre las relaciones entre ciudades. Resultó revelador descubrir que estos son tremendamente limitados a escala mundial, debido a que siendo las entidades públicas de escala subnacional, nacional u organismos supranacionales las únicas con capacidad para levantar datos de tal magnitud, los originan para la escala de su jurisdicción, y dejan de lado indicadores que permitan medir los flujos y relaciones entre ciudades.

En relación con los estudios sobre impactos territoriales de las vías, resultan pertinentes los realizados desde el centro de investigación TRANSyT, de la Universidad Politécnica de Madrid y especialmente el de López, Ortega y Condeço-Melhorado (2009), centrado en los cambios en la conectividad y los efectos de desbordamiento en las regiones del Proyecto Estratégico de Infraestructuras y Transporte (PEIT) de España, que intervendría carreteras y ferrocarriles por todo el país en el período 2005-2020. Su propósito fue brindar herramientas para identificar afectaciones en la cohesión regional, así como posibles efectos de desbordamiento. Tres indicadores allí planteados resultarían de gran importancia para investigaciones similares en nuestro país, siempre que se contara con las bases de información estadística desagregada para su estudio. Son esos: el indicador de eficiencia, el de accesibilidad agregada que es una variación del anterior, y el que mide el efecto de desbordamiento. En el caso de estudio de esta investigación solo se hizo un acercamiento parcial al indicador de eficiencia.

Con un enfoque similar al anterior, la investigación realizada por López, Ortega y Condeço-Melhorado (2009) aborda la accesibilidad de los distintos 
centros poblados de la comunidad de Castilla y León en España, a partir de indicadores de accesibilidad agregados. Su particularidad frente al trabajo anterior es la escala espacial de análisis (circunscrita a una comunidad autónoma) y la adición de una evaluación sobre el impacto ambiental del Proyecto Estratégico de Infraestructuras y Transporte. Los datos sobre clasificación de coberturas del suelo permitirían hacer una valoración del impacto sobre ecosistemas de diferente relevancia, e identificar los sitios donde sería pertinente implementar un instrumento legal de protección ambiental frente a las grandes obras de infraestructura.

Por otra parte, el trabajo de Kanitscheider (2010) compara dos regiones de montaña muy contrastantes. Por un lado, los Alpes europeos y por otro los Andes latinoamericanos. La comparación se hace en relación con: paisaje natural, infraestructura, volumen de tráfico, condiciones técnicas de los vehículos, así como en las redes urbanas, económicas y los sistemas de estructuras políticas. Las diferencias entre estas dos redes viales están dadas principalmente en términos de longitud, superficie, área, orientación, topografía, clima, localización de actividades económicas, infraestructura vial, población. De este trabajo incorporamos el concepto "tráfico de tránsito" entendido como aquel que atravesando una región ni se origina ni finaliza allí. Solo la atraviesa.

La calidad, multimodalidad y estabilidad física e institucional del corredor alpino contrasta con las deficiencias en esos aspectos de la ruta de los Andes y explica en parte las diferentes percepciones que se tienen en ambos lugares. Mientras en el espacio alpino, el término tráfico de tránsito se asocia con efectos negativos como el ruido y la contaminación atmosférica, en la cordillera de los Andes el discurso político relacionado con el término tránsito de transporte; cuyo significado es similar al de tráfico de tránsito, se asocia al mejoramiento de la infraestructura vial como factor clave en el desarrollo regional, principalmente en las regiones periféricas. Ejemplo de ese discurso es la IIRSA (Iniciativa para la Integración de la Infraestructura Regional Suramericana).

Observamos que diferentes tipos de territorios no solo tienen diferentes percepciones sobre las vías, sino que de acuerdo con sus características reciben impactos diferentes. Eso también ocurre en casos más cercanos, como el mencionado por Pereira de Brito (2012) quien nos ilustra sobre los cambios producidos a lo largo de la ruta Belén-Brasilia en términos de los procesos de colonización y nuevos asentamientos surgidos con su implementación, pero también sobre el surgimiento de nuevos conflictos territoriales. Por su parte, Díaz (2012) estudia el efecto de las vías variantes que se han ido construyendo con el paso de los años en inmediaciones del núcleo urbano de la ciudad de Tunja (Colombia), y como es hacia allí que van produciéndose los crecimientos más importantes de esa ciudad.

A continuación se presenta el estudio de caso seleccionado, que inicia con una caracterización de cada una de las tres rutas estudiadas y continúa con el análisis y presentación de hallazgos de los indicadores de cada una de las variables consideradas (variable histórica, variable geográfica, variable demográfica y variable económica). El texto cierra con las conclusiones finales. 

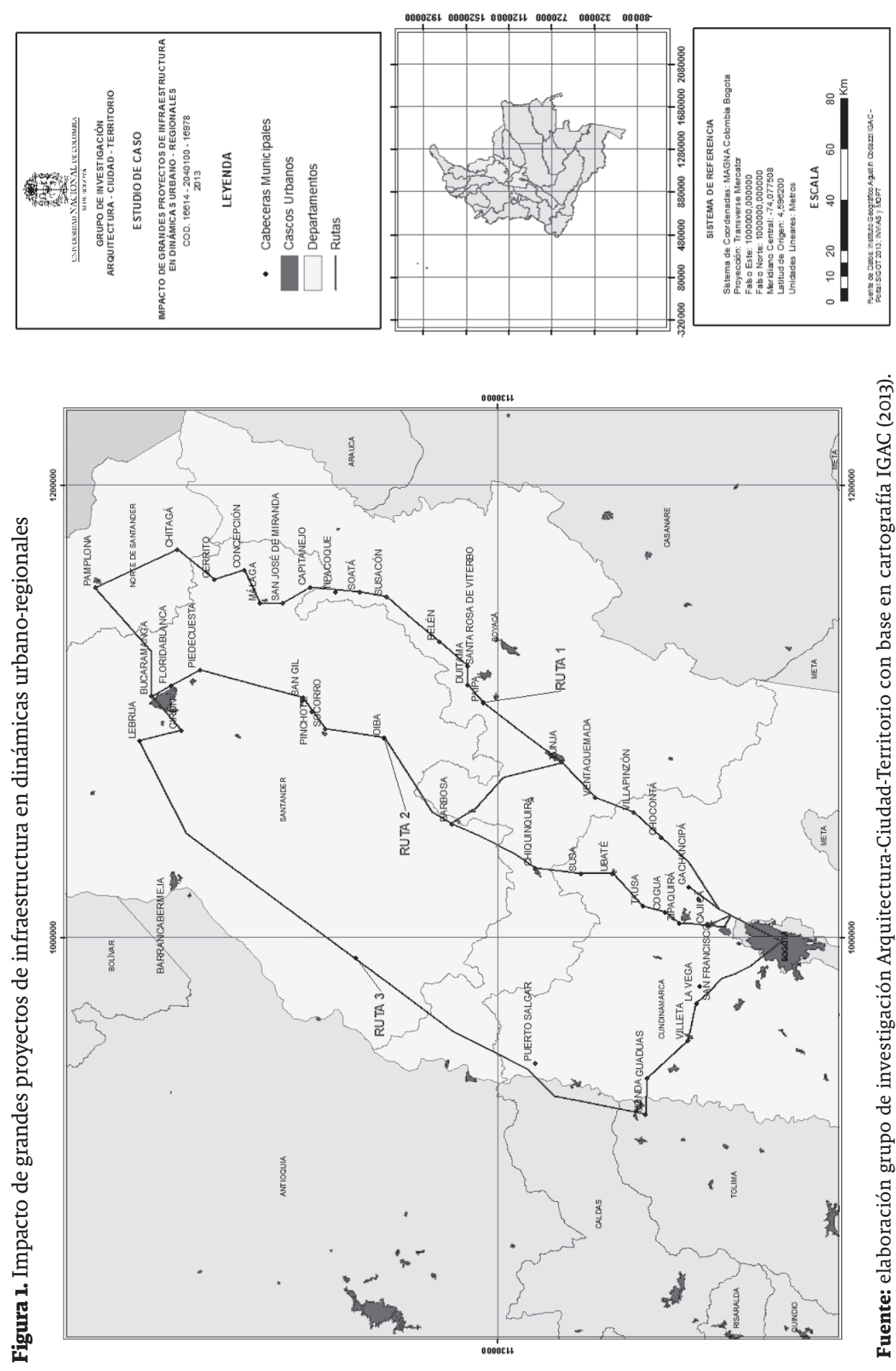


\section{Caracterización de cada una de las tres rutas del corredor Bogotá-Bucaramanga (Figura 1)}

\section{Troncal Oriental - ruta 55}

Esta antigua vía unía originalmente a Bogotá con Cúcuta a través de Pamplona y hacía un desvío de 125 km para llegar a Bucaramanga. Según Pachón y Ramírez $(2006,67)$ la Ley 88 de 1931 adoptó un nuevo plan de carreteras nacionales, en el que se definieron tres troncales longitudinales. Una de ellas, la troncal oriental Bogotá-Tunja-Pamplona-Cúcuta con una longitud de $634 \mathrm{~km}$. El mismo estudio menciona más adelante: "El gobierno del general Reyes inició en 1904 la carretera Troncal del Norte, esta vía fue para aquella época la más importante del país y se terminó en 1934, casi treinta años después de iniciada" (Pachón y Ramírez 2006, 77). Una de sus características es que a pesar de estar ubicada en áreas montañosas, escarpadas e inestables de la Cordillera Oriental cercanas a páramos, tuvo una gran importancia nacional, derivada del hecho de tener asentada allí, desde tiempos prehispánicos, la mayor cantidad de población y ser en épocas coloniales una vía de intercambio de artículos y mercancías provenientes del Caribe.

Para nuestro estudio llamaremos ruta 1 a esa vía, que en la actualidad atraviesa o bordea los cascos urbanos de los siguientes 21 municipios: Bogotá, Tocancipá, Gachancipá, Chocontá, Villapinzón, Ventaquemada, Tunja, Paipa, Duitama, Santa Rosa, Belén, Susacón, Soatá, Tipacoque, Capitanejo, San José de Miranda, Málaga, Concepción, Cerrito, Chitaga, Pamplona (en esta ciudad se sigue a Bucaramanga o a Cúcuta).

\section{Troncal Central ruta nacional 45A}

La segunda vía que se va consolidando es la que en adelante llamaremos ruta 2. Esta vía establece una forma directa de llegar a Bucaramanga desde Bogotá. La necesidad de construir una ruta de conexión directa entre Bogotá y Bucaramanga, se produce con la fundación y ascenso de esta última en las jerarquías urbanas, hecho que ocurre a finales del siglo XIX de la mano de la economía del café. La vía fue construyéndose por tramos; el primero, que conecta Tunja con Barbosa, se construyó entre los años 60 y 70 del pasado siglo. En las décadas de 1980 y 1990 se construye una variante que une Tunja con Chiquinquirá. El tramo Chiquinquirá-Barbosa, que evita el paso por Tunja, quedó terminado hacia finales de los años de 1990, aun cuando ese paso sigue siendo utilizado por el trasporte de pasajeros dada la dinámica alrededor de Tunja como capital del departamento de Boyacá. En el momento actual, el recorrido directo pasa por los siguientes 18 municipios: Bogotá, Cajicá, Zipaquirá, Cogua, Tausa, Sutatausa, Ubaté, Carmen de Carupa, Chiquinquirá, Barbosa, Santana, Oiba, Socorro, San Gil, Aratoca, Piedecuesta, Floridablanca, Bucaramanga.

\section{Troncal de Magdalena Medio - ruta 45}

La vía más reciente es la conocida como la del Magdalena Medio que acá llamaremos ruta 3, al igual que la ruta 1 tampoco lleva directo a Bucaramanga, puesto que su destino final es la ciudad de Santa Marta, puerto marítimo sobre

3 Vía 55 en la nomenclatura vigente del Ministerio del Transporte. 
la Costa Atlántica. Sin embargo, desviando a la altura de la ciudad de Barrancabermeja se recorren $138 \mathrm{~km}$ hasta llegar a Bucaramanga.

Según la demarcación oficial, esta carretera está compuesta por un primer tramo que de Bogotá baja hasta Honda (ruta-50) y de allí en adelante se toma la ruta 45. Los dos tramos recorren los siguientes 11 municipios: Bogotá, El Rosal, San Francisco, La Vega, Villeta, Guaduas, Honda, Puerto Salgar, Lebrija, Girón, Bucaramanga. La construcción de esta vía fue propuesta por la Misión Harvard a finales de los años de 1960; su inicio se produjo en 1980 y para 1995 aún no se había concluido, a pesar de haberse mantenido como vía prioritaria en los planes nacionales de infraestructura desde 1986 hasta 1994. La vía se ubica en un importante corredor que comunica el interior del país con los puertos de la costa norte y con Venezuela, lo que mejora en forma radical la conexión entre Bogotá y Bucaramanga, gracias al acortamiento del anterior recorrido que transcurría en su mayor parte por terreno montañoso (Pachón y Ramírez 2006).

\section{Análisis de variables}

\subsection{Variable histórica}

\section{a. Año de fundación}

Como ya se ha mencionado, las tres rutas se fueron construyendo en épocas sucesivas, siendo la 1 la más antigua (prehispánica) y la 3 la más reciente (finales del siglo XX). Lo primero que resalta en la tabla 1 es la relación entre cantidad de poblaciones de fundación antigua y ruta más antigua. También resalta el hecho de que la vía más reciente tiene menos poblaciones directamente conectadas a ella, lo cual tiene que ver con el hecho de que las rutas iniciales estaban más al servicio de dinámicas regionales: "En esta región se desarrolló un amplio proceso fundacional y se establecieron las bases de la primera red urbana regional" (Zambrano 1993, 43). De allí la importancia de conectar directamente las poblaciones, mientras que las vías recientes tienen que ver más con el denominado "tráfico de tránsito" (Kanitscheider 2010) que está más ligado con dinámicas de exportación; por ello su efectividad está en términos de hacer más directo el trayecto entre un origen y un destino -en nuestro caso Bogotá- y un punto de exportación/importación y no en conectar la mayor cantidad de municipios.

La tabla 2 evidencia lo mencionado anteriormente sobre la relación entre cantidad de poblaciones ubicadas sobre lo que ha sido la ruta 1 y la antigüedad en su fundación: de los 22 municipios, 16 fueron fundados con anterioridad al siglo XIX. De los departamentos servidos por las tres rutas, el departamento de Cundinamarca, cuya mayor dinámica está jalonada por el impulso de crecimiento de Bogotá4, es el único que aumenta el número de municipios servidos por la vía más reciente (ruta 3). Mientras la ruta 1 conectaba cinco municipios de este departamento, las rutas 2 y 3 conectan a siete; Santander baja de ocho municipios conectados por medio de la ruta 1 a tres municipios en las rutas 2 y 3, y Boyacá, que en la ruta 1

4 La preeminencia que va adquiriendo la capital del país va jalonando al departamento de Cundinamarca, del cual Bogotá también es su capital. 
Tabla 1. Municipios del corredor vial Bogotá-Bucaramanga (Colombia), según ruta y año de fundación

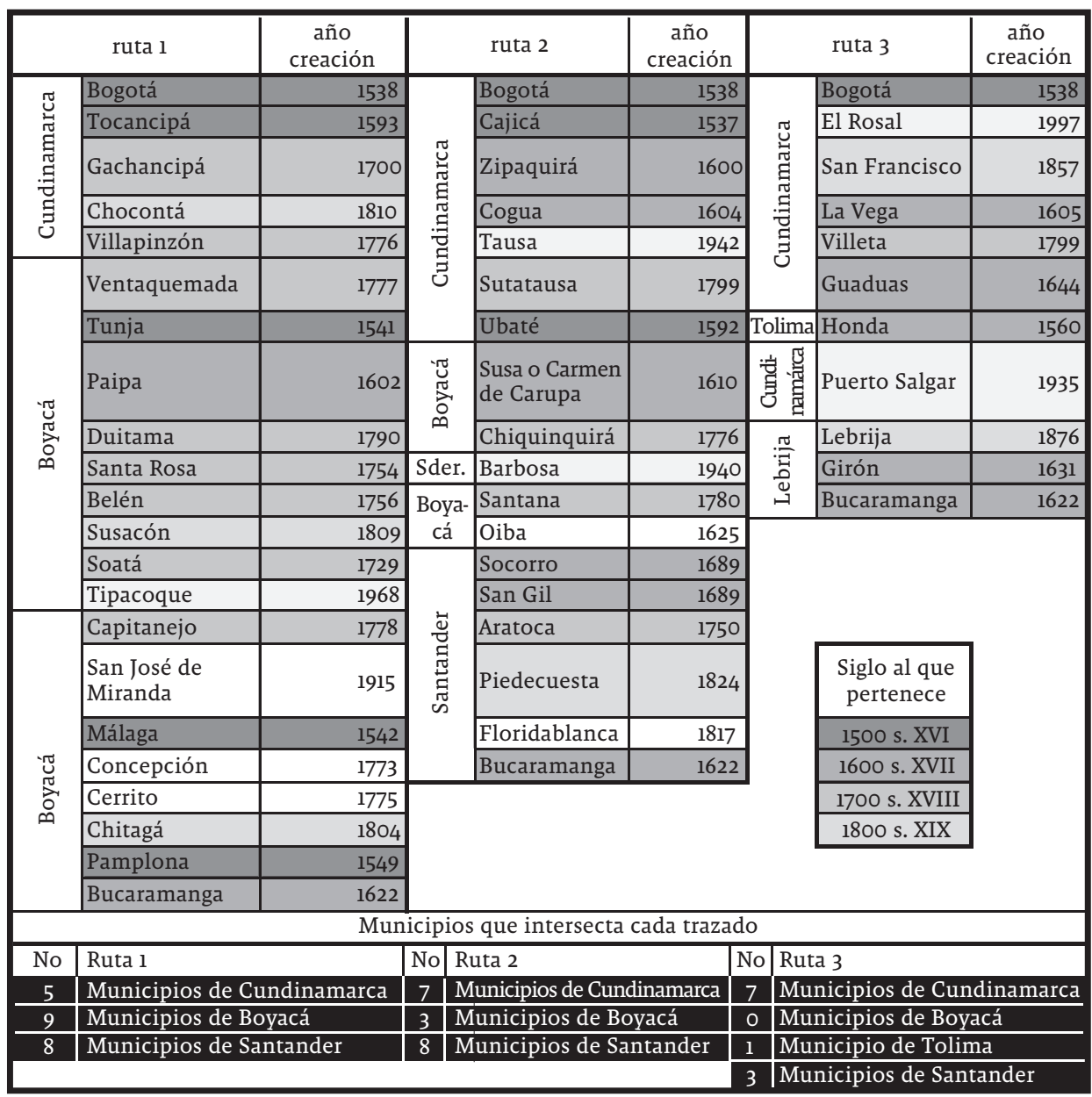

Fuente: elaboración grupo de investigación Arquitectura-Ciudad-Territorio, basado en datos (DANE -Departamento Administrativo Nacional de Estadística- 1985; 1993; 2005) y Zambrano (1993).

tenía nueve municipios conectados disminuye a tres en la ruta 2 y a cero en la ruta 3. Esto nos permite aludir al proceso de despoblamiento que sufrió la Cordillera Oriental a partir de la mitad del siglo XIX (Zambrano 1993) y al cambio de jerarquías, como se mostrará a continuación.

\section{b. Estructuración de la red vial}

Los mapas realizados a partir de la información contenida en el libro La infraestructura de transporte en Colombia durante el siglo XX (Pachón y Ramírez 2006) muestran la estructuración histórica de la red vial en este sector, identificando los tramos que se van interviniendo a partir de 1950 con el objeto de pavimentar vías existentes o abrir nuevas. Cabe aclarar que los mapas resaltan las intervenciones que se realizan en el territorio desde 1950 a partir del 
Tabla 2. Municipios del corredor vial Bogotá-Bucaramanga por ruta y año de fundación

\begin{tabular}{|c|c|c|c|c|c|c|c|c|}
\hline \multicolumn{3}{|c|}{ Ruta 1. 22 municipios } & \multicolumn{3}{|c|}{ Ruta 2. 18 municipios } & \multicolumn{3}{|c|}{ Ruta 3. 11 municipios } \\
\hline \multirow{5}{*}{$\begin{array}{l}\text { Cundinamarca } \\
5 \text { municipios }\end{array}$} & siglo XVI & 2 & & siglo XVI & 3 & & siglo XVI & 1 \\
\hline & siglo XVII & 0 & Cundinamarca & siglo XVII & 2 & Cundinamarca & siglo XVII & 2 \\
\hline & siglo XVIII & 2 & 7 municipios & siglo XVIII & 1 & 7 municipios & siglo XVIII & 1 \\
\hline & siglo XIX & 1 & & siglo XIX & 0 & & siglo XIX & 1 \\
\hline & siglo XX & 0 & & siglo XX & 1 & & siglo XX & 2 \\
\hline \multirow{5}{*}{$\begin{array}{c}\text { Boyacá } \\
9 \text { municipios }\end{array}$} & siglo XVI & 1 & & siglo XVI & 0 & & siglo XVI & 1 \\
\hline & siglo XVII & 1 & Boyacá & siglo XVII & 1 & Tolima & siglo XVII & 0 \\
\hline & siglo XVIII & 5 & 3 municipios & siglo XVIII & 2 & 1 municipio & siglo XVIII & 0 \\
\hline & siglo XIX & 1 & & siglo XIX & 0 & & siglo XIX & 0 \\
\hline & siglo $\mathrm{XX}$ & 1 & & siglo XX & 0 & & siglo XX & 0 \\
\hline \multirow{5}{*}{$\begin{array}{c}\text { Sandander } \\
8 \text { municipios }\end{array}$} & siglo XVI & 2 & & siglo XVI & 0 & & siglo XVI & 0 \\
\hline & siglo XVII & 1 & Sandander & siglo XVII & 4 & Sandander & siglo XVII & 2 \\
\hline & siglo XVIII & 3 & 8 municipios & siglo XVIII & 1 & 3 municipios & siglo XVIII & 0 \\
\hline & siglo XIX & 1 & & siglo XIX & 2 & & siglo XIX & 1 \\
\hline & siglo XX & 1 & & siglo XX & 1 & & siglo XX & 0 \\
\hline
\end{tabular}

Fuente: elaboración grupo de investigación Arquitectura-Ciudad-Territorio.

primer plan nacional de vías. Se muestra en ellos la introducción del pavimento, nuevo material que permite una mejora en la red vial, a diferencia de las anteriores que solo eran afirmadas. Por tal motivo, si bien la ruta 55 se realizó entre 1904 y 1934, tal y como lo referencia el estudio de Pachón y Ramírez (2006) el mapa muestra lo que se va pavimentando y ajustando y el trazado de esta y las otras dos rutas (figura 2-1 a 2-5). Otro aspecto a resaltar, derivado del estudio de Pachón y Ramírez (2006) se relaciona con la situación que se presentó como consecuencia del invierno de 1949 y 1950, en la que buena parte de la red vial desapareció e hizo necesario reconstruirla. Lo irónico del caso es que este tipo de situaciones siguen ocurriendo sesenta años después, como sucedió durante el invierno del 2010/2011 que dejó inservible una buena cantidad de vías en el país.

El proceso de estructuración o pavimentación de la red vial de los años cincuenta del siglo XX hasta el 2000 va haciendo explícita la pérdida de interés por la ruta histórica 55, posiblemente en razón al crecimiento demográfico negativo que empieza a producirse en los municipios por ella servidos y el consecuente despoblamiento que experimentó esta zona con el ascenso de la economía cafetera en las vertientes y las emigraciones que esto provocó. Se señaló anteriormente un patrón negativo recurrente en el desarrollo del país que consiste en la forma como se van abandonando zonas que tuvieron alguna importancia en el pasado y se las deja solas en su proceso de decaimiento, sin plantearse políticas de reconversión productiva de sus poblaciones. Este proceso va acumulando un saldo negativo en desequilibrio territorial e inequidad que debe replantearse. 


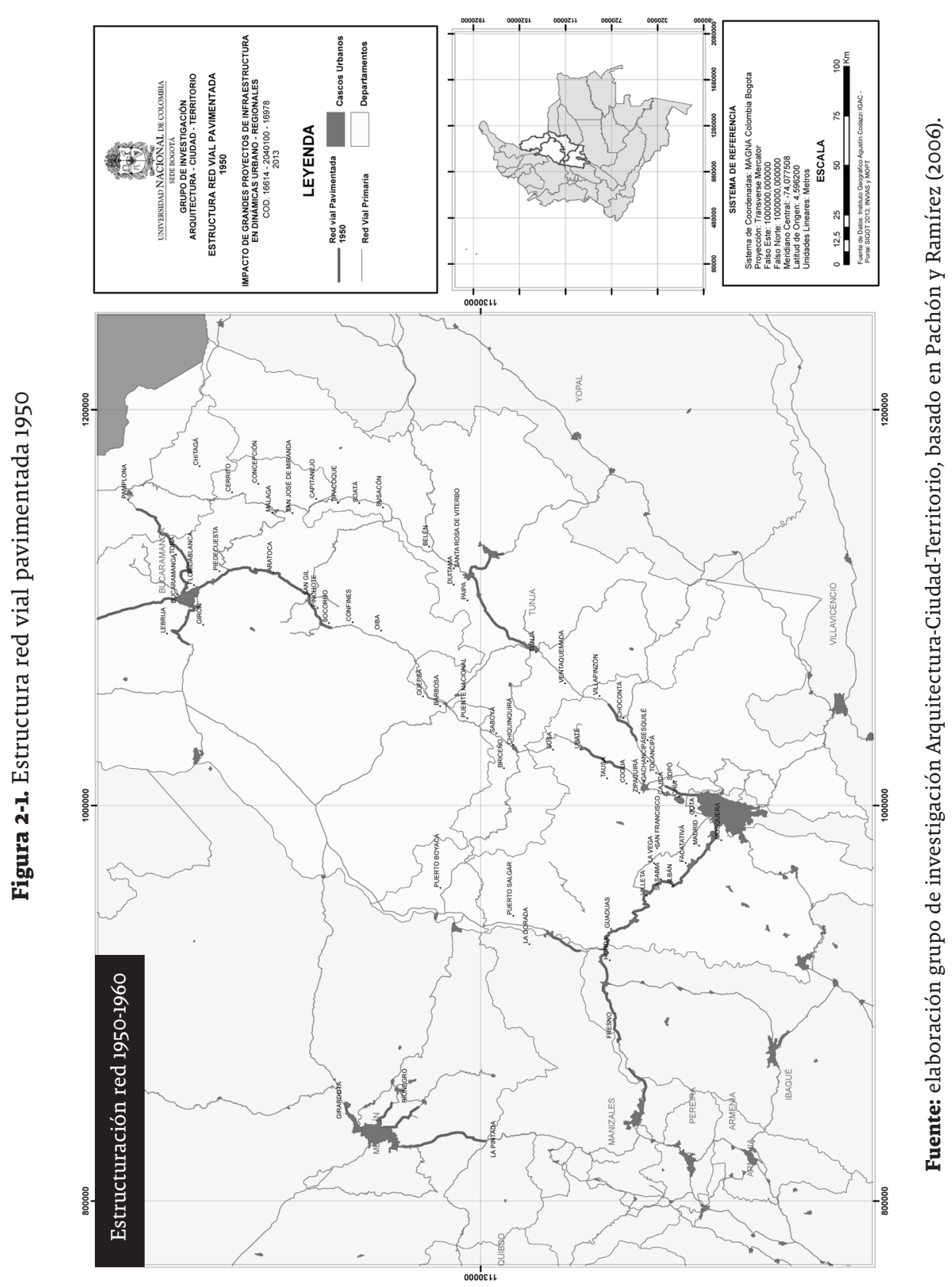




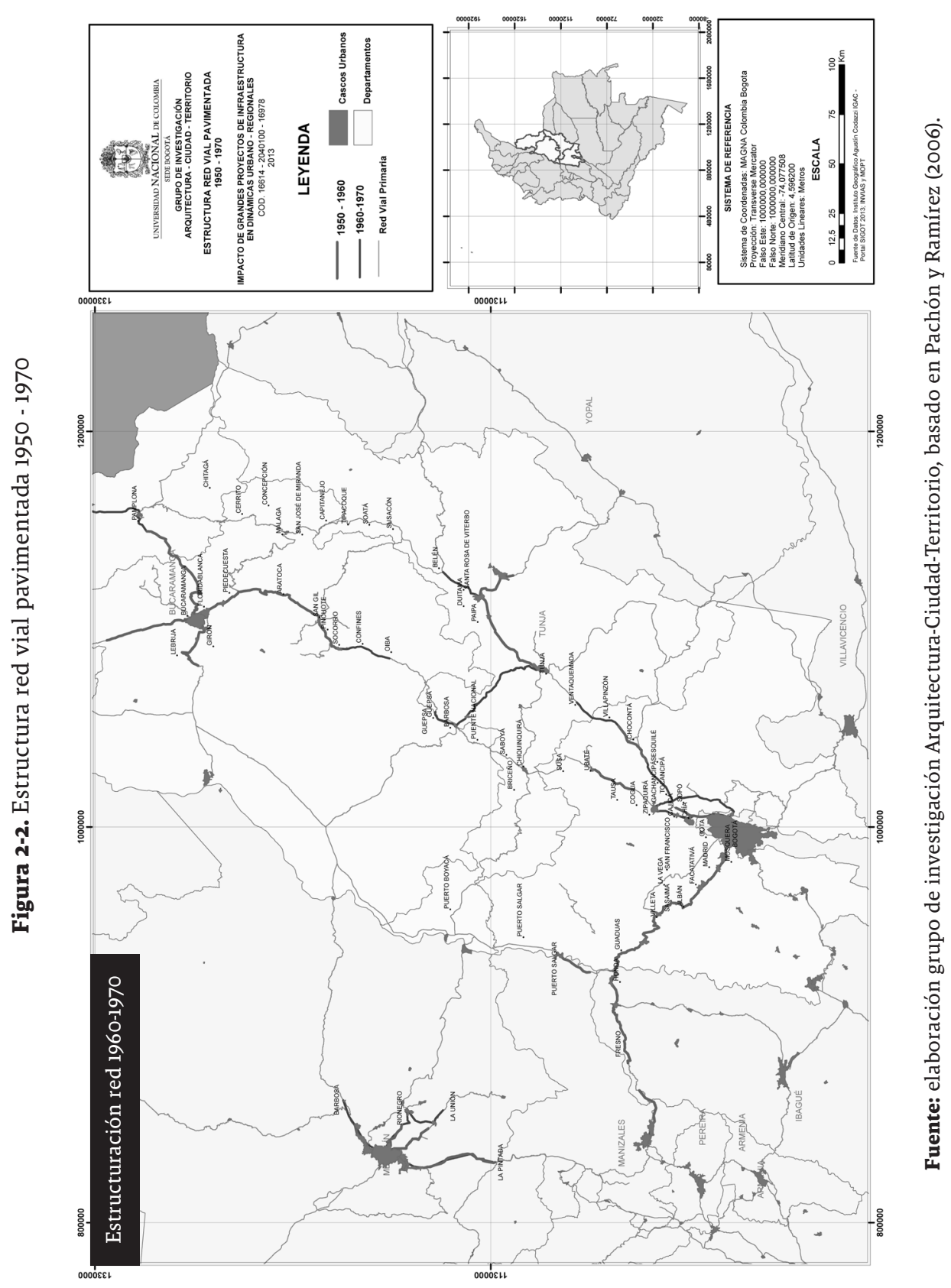




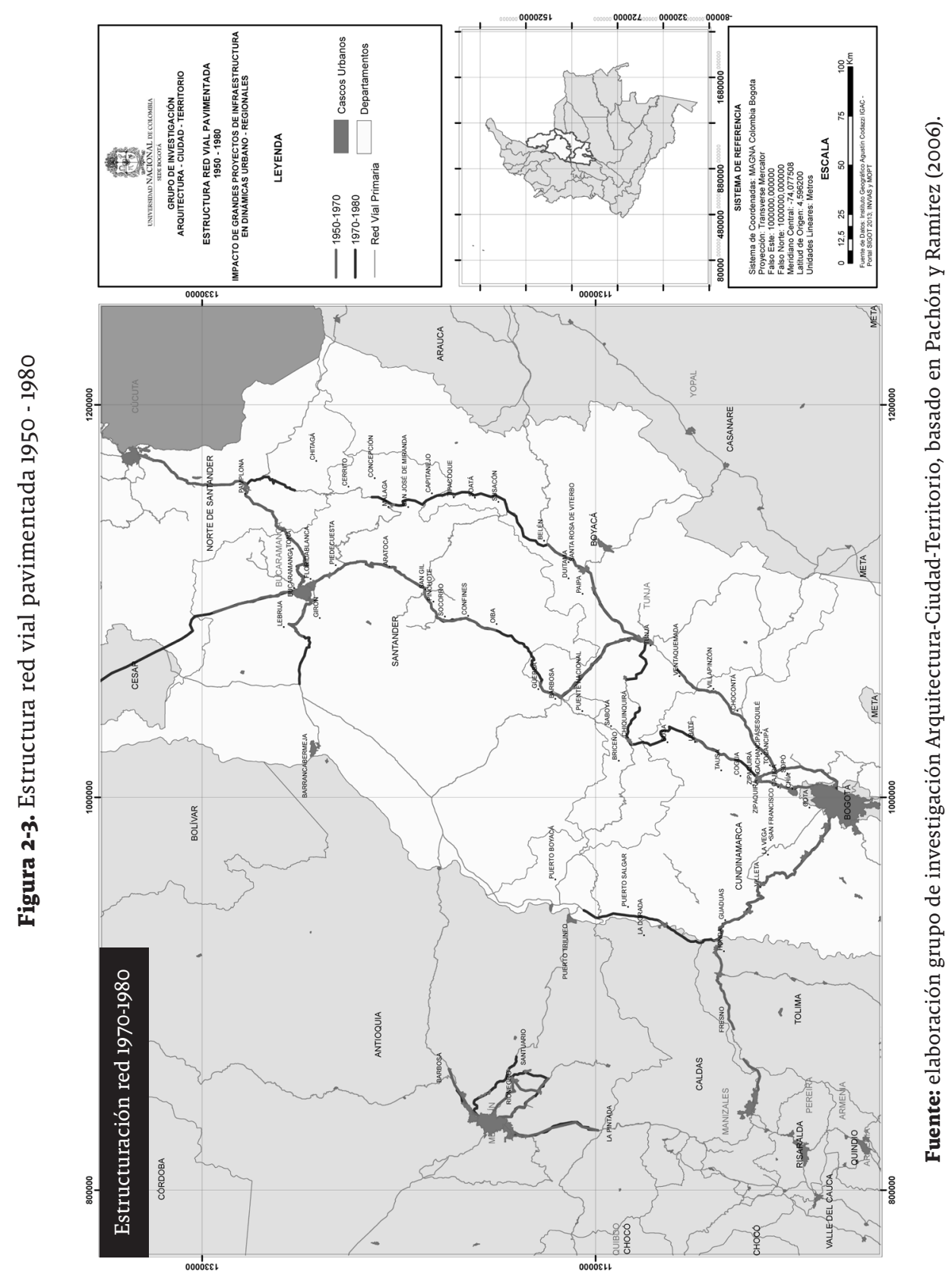




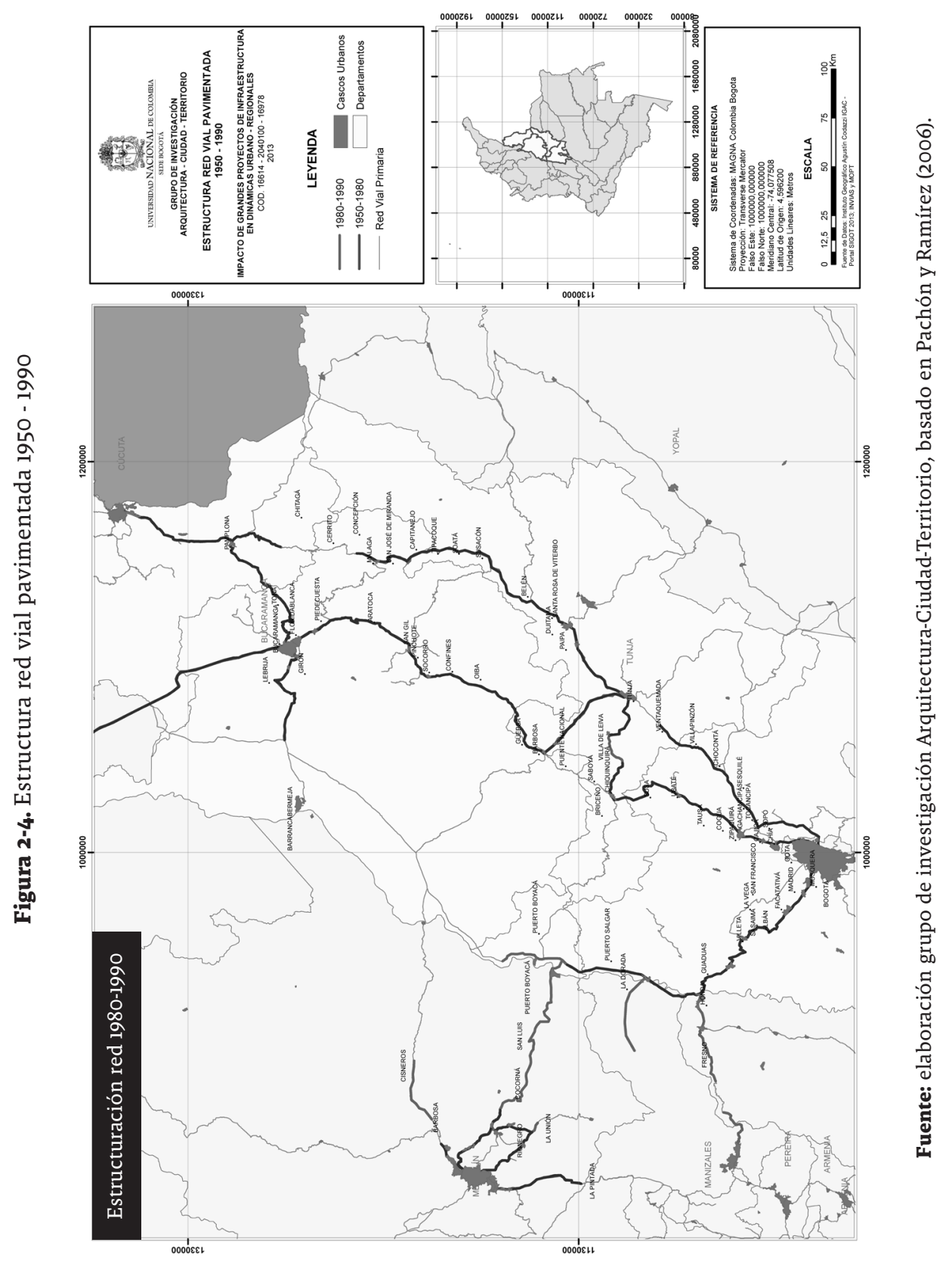




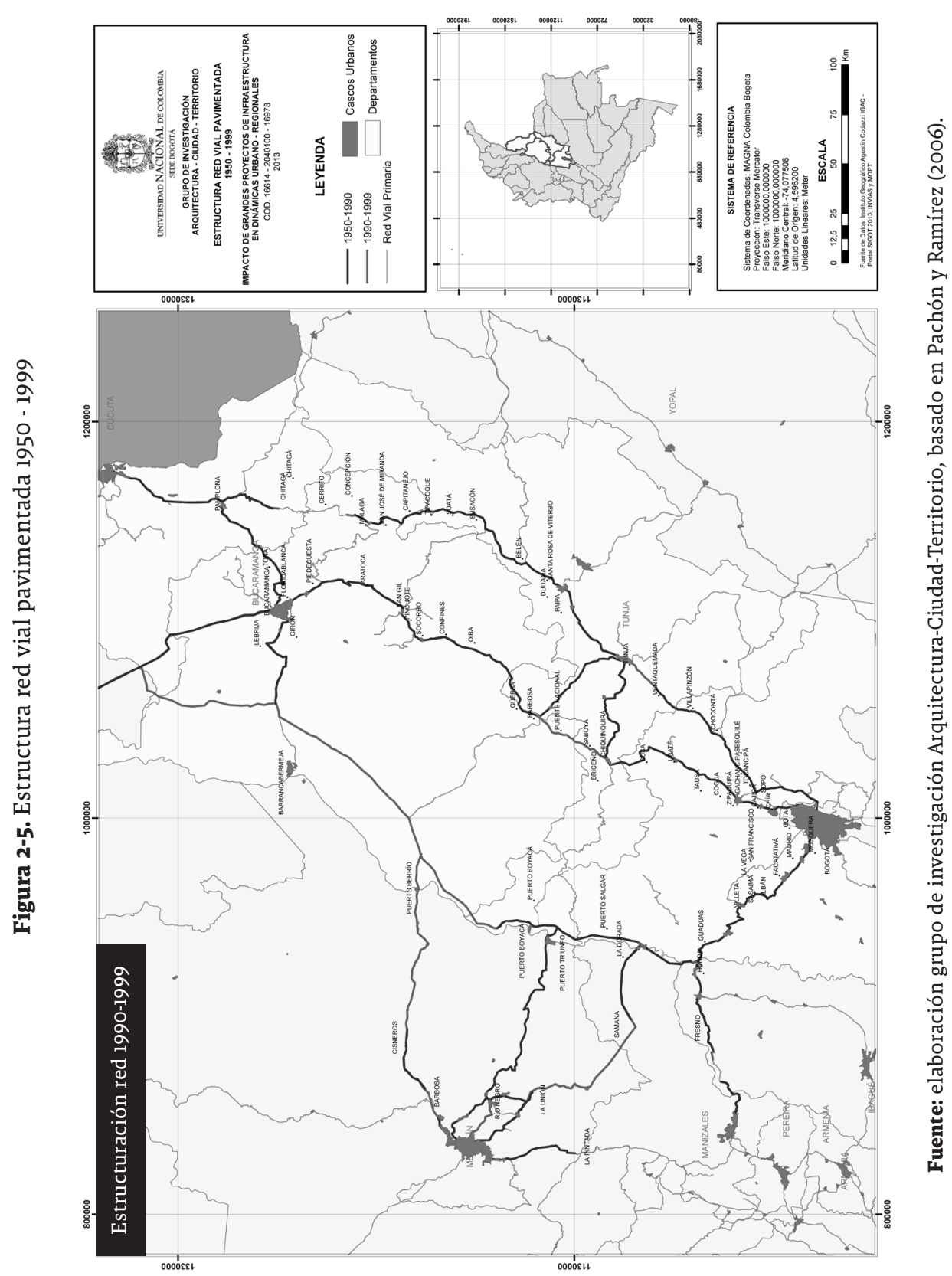




\subsection{Variable geográfica}

\section{a. Relieve/topografía}

El mapa de la figura 3 y los dos cortes transversales a la Cordillera muestran el descenso paulatino, en términos de relieve, que experimentan las tres rutas. De las zonas escarpadas de los páramos de alta montaña de la Cordillera Oriental, asentamientos tradicionales de la confederación Muisca y las tribus Guane de Santander de la época prehispánica, se va bajando a niveles altitudinales medios en el siglo XX (ruta 2), para llegar en la actualidad a las zonas planas que bordean el río Magdalena (ruta 3). Este cambio va paralelo a la disminución de jerarquía de los municipios de la ruta 1 que, al igual que la ruta que los unía, mantuvieron su importancia hasta las tres primeras décadas del siglo XX, tal y como se estableció en la investigación ya citada de Pachón y Ramírez (2006), independientemente de las notables dificultades que experimenta una carretera que va bordeando las alturas de los páramos.

La ruta 2 mantiene algunos tramos entre Cundinamarca y Boyacá en zona de montaña (corte 2), dejando ver que hasta ese momento pesaba más la necesidad de unir los municipios allí ubicados que las dificultades ocasionadas por la topografía. No pasa lo mismo cuando la vía llega al departamento de Santander, donde muy de la mano de la economía del café se genera un proceso de poblamiento de la vertiente occidental de la cordillera Oriental; la vía empieza a ubicarse sobre una cota de nivel más baja (corte 1 ).

La ruta 3, de más reciente surgimiento, marca el proceso actual de privilegiar las zonas planas, más eficientes y económicas en términos viales y de transporte de carga y poseedoras de riquezas que resultan importantes de integrar a una red vial de mejor calidad. El empuje de la ciudad de Barrancabermeja, que desde los años de 1930 cuenta con la principal refinería petrolera del país, empieza a hacer viable esa nueva vía, pero será la política de apertura económica con su necesidad de mejorar la conexión con los puertos y el interior del país, lo que dará el impulso final para su construcción.

Al revisar el proceso de poblamiento, que de la mano de nuevos desarrollos económicos va bajando de las montañas a las planicies, y a la par va construyendo vías que abran estos territorios cálidos poco habitados, muestra simultáneamente un patrón de abandono y decaimiento de antiguas poblaciones que va configurando unas condiciones de desequilibrio territorial aún no compensadas por políticas de reconversión económica de las rutas y poblaciones olvidadas.

\subsection{Variable demográfica}

\section{a. Población y tasas de crecimiento intercensal}

Un aspecto que resulta indicativo del impacto de las infraestructuras viales sobre los municipios a los que sirven es el relacionado con sus dinámicas demográficas. Por tal motivo, en las tablas 3, 4 y 5 elaboradas para cada una de las tres rutas se ha consignado la siguiente información: una parte de la tabla muestra el dato de los tres últimos censos de población del DANE y la otra, el análisis de las tasas de crecimiento intercensal. Los datos en negrilla señalan aquellos municipios cuya tasa de crecimiento es negativa.

Lo que podemos deducir para la ruta 1 (tabla 3) es que la tendencia decreciente que ya se observaba en las tasas 1985/1993 en municipios como Tipacoque, Capitanejo, San José de Miranda, Concepción y Cerrito, se generaliza en todos los municipios ubicados en la parte norte de esta vía para el periodo intercensal 1993/2005, siendo el 
Figura 3. Eje de infraestructura vial Bogotá-Bucaramanga (Colombia). Rutas según relieve (dos cortes transversales)

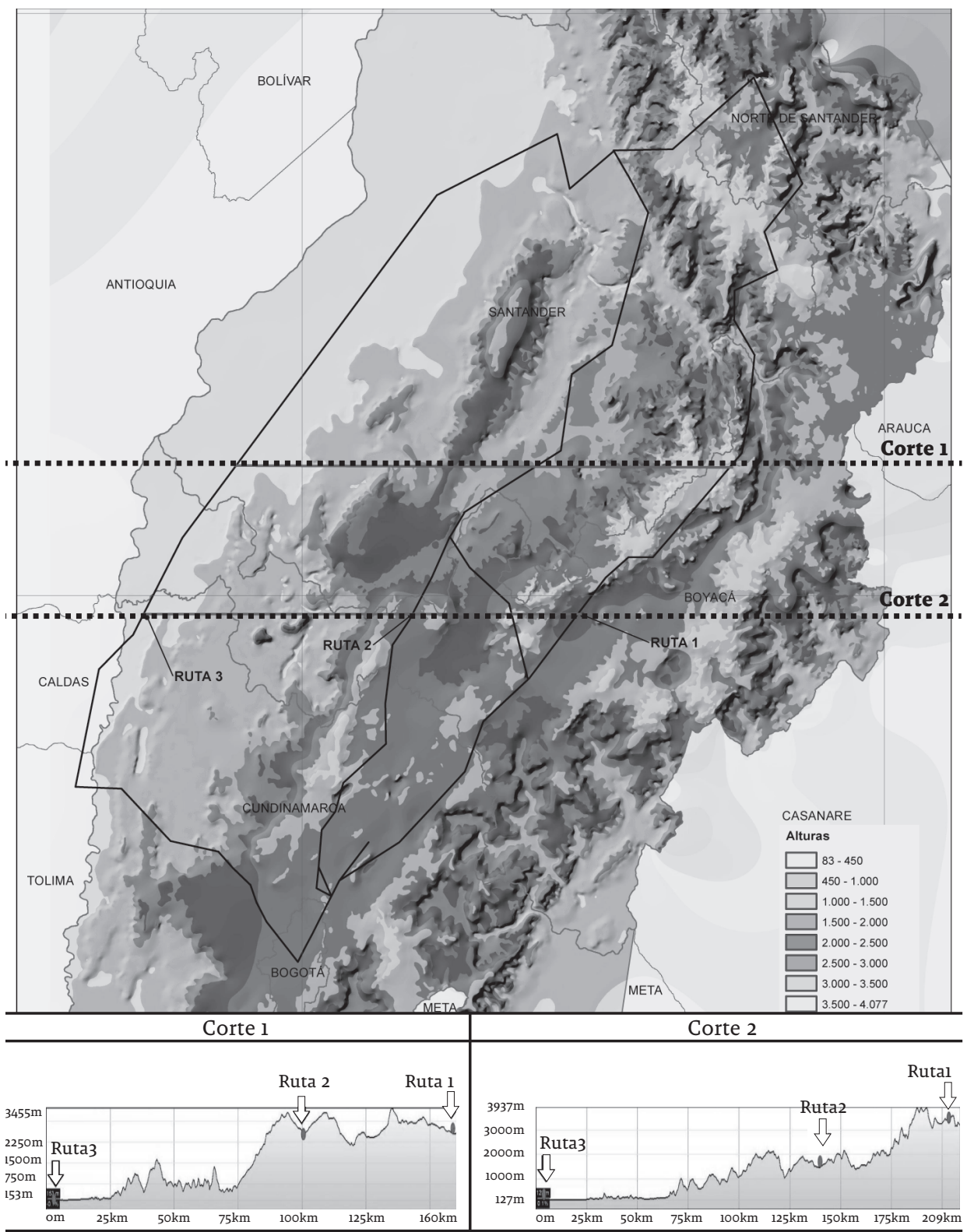

Fuente: elaboración grupo de investigación Arquitectura-Ciudad-Territorio con base en cartografía IGAC (2013).

caso más dramático el del municipio de Soatá, antigua capital de provincia. Esta tendencia va en paralelo con el afianzamiento de la ruta 2, que como se mostró anteriormente ocurre en los años de 1990. En otras palabras, la nueva ruta le quita dinámica a los municipios ubicados sobre la antigua, que entran en decadencia demográfica, 
ocasionando con ello un desinterés por brindar un mantenimiento y actualización de especificaciones a la ruta, y entrando en un círculo en el cual decrece la población y seguramente la actividad económica y eso no presiona por el mejoramiento de la vía ocasionando a su vez poco interés para ubicarse en ellos y cambiar su dinámica.

La anterior observación se corrobora con los datos demográficos de los municipios ubicados en la ruta 2 (tabla 4). Resalta el incremento de población en dos municipios claves de esta ruta: Chiquinquirá y Barbosa, cuyas tasas de crecimiento se duplican de un período a otro y explican el interés por generar las vías transversales que los unan con Tunja.

También observamos que en mayor o menor medida todos los municipios crecen a la par con la consolidación de la nueva ruta, mientras que una porción importante de los municipios de la ruta antigua decrecen. Esto nos permite verificar el impacto de las vías en las dinámicas urbano-regionales, y demostrar que la implementación de una nueva ruta va de la mano de dos situaciones contrarias: de una parte acentúa la dinámica sobre la nueva vía, y de otra contribuye al decaimiento de los municipios ubicados sobre la anterior. La excepción se presenta en aquellos tramos donde las dinámicas económicas se acomodan a los nuevos requerimientos de la economía o mantienen algún interés para ella, como puede ocurrir en la ruta 1 sobre el tramo que de Bogotá va hasta Duitama.

Tabla 3. Población y tasas de crecimiento demográfico de la ruta l del corredor vial Bogotá-Bucaramanga

\begin{tabular}{|c|c|c|c|c|c|c|}
\hline \multicolumn{5}{|c|}{ Cantidad de población } & \multicolumn{2}{|c|}{$\begin{array}{c}\text { Tasa de crecimiento } \\
\text { intercensal }\end{array}$} \\
\hline No & Municipio & Censo 1985 & Censo 1993 & Censo 2005 & $1985 / 1993$ & $1993 / 2005$ \\
\hline 1 & Bogotá & 4.225 .649 & 5.413 .484 & 6.840 .116 & 0,281 & 0,264 \\
\hline 2 & Tocancipá & 8.814 & 14.328 & 24.154 & 0,626 & 0,686 \\
\hline 3 & Gachancipá & 4.386 & 5.994 & 10.886 & 0,367 & 0,816 \\
\hline 4 & Chocontá & 16.947 & 15.320 & 19.512 & $-0,096$ & 0,274 \\
\hline 5 & Villapinzón & 14.987 & 14.293 & 16.573 & $-0,046$ & 0,160 \\
\hline 6 & Ventaquemada & 12.190 & 11.231 & 14.404 & $-0,079$ & 0,283 \\
\hline 7 & Tunja & 93.966 & 108.138 & 154.066 & 0,151 & 0,425 \\
\hline 8 & Paipa & 21.669 & 22.195 & 27.766 & 0,024 & 0,251 \\
\hline 9 & Duitama & 75.047 & 94.874 & 107.417 & 0,264 & 0,132 \\
\hline 10 & Santa Rosa & 11.399 & 11.845 & 13.249 & 0,039 & 0,119 \\
\hline $\mathrm{ll}$ & Belén & 10.303 & 12.673 & 9.041 & 0,230 & $-0,287$ \\
\hline 12 & Susacón & 4.107 & 4.879 & 3.698 & 0,188 & $-0,242$ \\
\hline 13 & Soatá & 17.676 & 17.706 & 9.313 & 0,002 & $-0,474$ \\
\hline 14 & Tipacoque & 5.263 & 4.372 & 3.855 & $-0,169$ & $-0,118$ \\
\hline 15 & Capitanejo & 8.036 & 7.112 & 6.152 & $-0,115$ & $-0,135$ \\
\hline 16 & San José de Miranda & 7.127 & 5.965 & 4.855 & $-0,163$ & $-0,186$ \\
\hline 17 & Málaga & 16.762 & 18.747 & 18.706 & 0,118 & $-0,002$ \\
\hline 18 & Concepción & 7.860 & 7.341 & 5.908 & $-0,066$ & $-0,195$ \\
\hline 19 & Cerrito & 6.586 & 6.624 & 6.319 & 0,006 & $-0,046$ \\
\hline 20 & Chitagá & 11.614 & 10.823 & 10.179 & $-0,068$ & $-0,060$ \\
\hline 21 & Pamplona & 41.773 & 47.360 & 53.158 & 0,134 & 0,122 \\
\hline 22 & Bucaramanga & 402.840 & 465.485 & 516.460 & 0,156 & 0,110 \\
\hline
\end{tabular}

Fuente: Fuente: elaboración grupo de investigación Arquitectura-Ciudad-Territorio basado en DANE (1951; 1964; 1973; 1985; 1993; 2005). 
Tabla 4. Población y tasas de crecimiento demográfico de la ruta 2 del corredor vial Bogotá-Bucaramanga

\begin{tabular}{|c|c|c|c|c|c|c|}
\multicolumn{9}{|c|}{ Cantidad de población } & \multicolumn{2}{c|}{$\begin{array}{r}\text { Tasa de crecimiento } \\
\text { intercensal }\end{array}$} \\
\hline No & Municipio & Censo 1985 & Censo 1993 & Censo 2005 & $1985 / 1993$ & $1993 / 2005$ \\
\hline 1 & Bogotá & 4.225 .649 & 5.413 .484 & 6.840 .116 & 0,281 & 0,264 \\
2 & Cajicá & 23.618 & 31.316 & 45.391 & 0,326 & 0,449 \\
3 & Zipaquirá & 60.202 & 75.166 & 101.562 & 0,249 & 0,351 \\
4 & Cogua & 12.632 & 13.390 & 18.276 & 0,060 & 0,365 \\
5 & Tausa & 6.763 & 6.560 & 7.715 & $-0,030$ & 0,176 \\
6 & Sutatausa & 3.868 & 3.871 & 4.742 & 0,001 & 0,225 \\
7 & Ubaté & 25.376 & 32.466 & 36.433 & 0,279 & 0,122 \\
8 & Carmen de Carupa & 6.236 & 7.290 & 9.782 & 0,169 & 0,342 \\
9 & Chiquinquirá & 35.807 & 41.437 & 55.797 & 0,157 & 0,347 \\
10 & Barbosa & 16.785 & 19.226 & 25.768 & 0,145 & 0,340 \\
11 & Santana & 7.011 & 7.439 & 7.853 & 0,061 & 0,056 \\
12 & Oiba & 9.309 & 9.839 & 10.983 & 0,057 & 0,116 \\
13 & Socorro & 24.013 & 25.055 & 29.076 & 0,043 & 0,160 \\
14 & San Gil & 33.351 & 37.955 & 43.519 & 0,138 & 0,147 \\
15 & Aratoca & 7.407 & 7.809 & 8.395 & 0,054 & 0,075 \\
16 & Piedecuesta & 50.853 & 80.898 & 117.405 & 0,591 & 0,451 \\
17 & Floridablanca & 148.205 & 199.426 & 254.600 & 0,346 & 0,277 \\
18 & Bucaramanga & 402.840 & 465.485 & 516.460 & 0,156 & 0,110 \\
\hline
\end{tabular}

Fuente: elaboración grupo de investigación Arquitectura-Ciudad-Territorio basado en DANE (1951; 1964; 1973; 1985; 1993; 2005).

Lo anterior nos permite aclarar que para el caso de la ruta 3 (tabla 5), terminada a finales de los años de 1990, el período 1993-2005 empieza a ser el momento de observar transformaciones, una de ellas es el surgimiento del municipio de El Rosal en 1997, que se segrega de Subachoque producto de las dinámicas metropolitanas que desde Bogotá van impactando sus municipios vecinos. Este hecho no se había observado en las rutas anteriores. Conviene recordar que estas divisiones surgen en el momento en que se produce un aumento en la dinámica económica del municipio original, lo que frecuentemente exacerba las luchas por el poder y la creación del nuevo ente territorial.

Otros municipios que a la par que se va consolidando la nueva vía incrementan su dinámica demográfica (aumento en sus tasas de crecimiento poblacional) son San Francisco, Guaduas y Puerto Salgar. La excepción se presenta en el municipio de Honda (puerto fluvial sobre el río Magdalena), que experimenta un descenso en su tasa de crecimiento y cuyas causas deben encontrarse en otras variables. Así, por ejemplo, en décadas recientes, la confrontación entre las guerrillas, el poder paramilitar y el poder del narcotráfico que agudizó el conflicto armado en esta zona del Magdalena Medio, muy posiblemente ha tenido alguna incidencia en el decaimiento de la ciudad de Honda, en la consolidación de esta nueva ruta, y en las dinámicas que sobre ella se dan. Sin embargo, la investigación de la cual, este estudio de caso es solo una parte, no planteó en esta fase abordar temas relacionados con la conflictividad social y la relación entre poder y espacio que si bien son absolutamente importantes, desbordaban los alcances propuestos. 
Tabla 5. Población y tasas de crecimiento demográfico de la ruta 3 del corredor vial Bogotá-Bucaramanga

\begin{tabular}{|c|c|c|c|c|c|c|}
\hline \multicolumn{5}{|c|}{ Cantidad de población } & \multicolumn{2}{|c|}{$\begin{array}{l}\text { Tasa de crecimiento } \\
\text { intercensal }\end{array}$} \\
\hline No & Municipio & Censo 1985 & Censo 1993 & Censo 2005 & $1985 / 1993$ & $1993 / 2005$ \\
\hline 1 & Bogotá & 4.225 .649 & 5.413 .484 & 6.840 .116 & 0,281 & 0,264 \\
\hline 2 & El Rosal & & & 13.502 & & \\
\hline 3 & San Francisco & 6.467 & 6.651 & 8.304 & 0,028 & 0,249 \\
\hline 4 & La Vega & 10.387 & 11.806 & 13.265 & 0,137 & 0,124 \\
\hline 5 & Villeta & 20.798 & 23.615 & 24.340 & 0,135 & 0,031 \\
\hline 6 & Guaduas & 23.874 & 24.882 & 31.831 & 0,042 & 0,279 \\
\hline 7 & Honda & 30.217 & 30.597 & 27.310 & 0,013 & $-0,107$ \\
\hline 8 & Puerto Salgar & 13.638 & 12.045 & 15.519 & $-0,117$ & 0,288 \\
\hline 9 & Lebrija & 23.825 & 27.114 & 30.980 & 0,138 & 0,143 \\
\hline 10 & Girón & 58.053 & 88.972 & 135.860 & 0,533 & 0,527 \\
\hline 11 & Bucaramanga & 402.840 & 465.485 & 516.460 & 0,156 & 0,110 \\
\hline
\end{tabular}

Fuente: elaboración grupo de investigación Arquitectura-Ciudad-Territorio basado en DANE (1951; 1964; $1973 ; 1985 ; 1993 ; 2005)$.

\subsection{Variable económica}

\section{a. Movilidad: flujos de tránsito. TPD y correlación con dinámica demográfica}

El tránsito promedio diario -TPD- es un indicador que permite identificar la cantidad de vehículos que se mueven sobre las vías. Esta información la viene tomando el Ministerio de Transporte a través del Instituto Nacional de Vías -Invías-, desde 1968. Los datos son establecidos a partir de mediciones en puntos determinados de las vías nacionales; allí se registra el dato total de vehículos que se mueven diariamente entre estos tramos, y se hace una discriminación entre automóviles, buses y camiones dada en porcentaje sobre el valor total. Para nuestras rutas de estudio se digitalizó la información de los años más cercanos o coincidentes con los censos de población ${ }^{5}$.

El las figuras 4-1 a la 4-5, que incluye, además de los valores del TPD, la correlación con las dinámicas demográficas anteriormente presentadas, permite ver gráficamente el proceso de despoblamiento que está sucediendo en la mayoría de los municipios y su consecuente aglomeración en los extremos: Bogotá, Bucaramanga y Cúcuta, más al norte; sin embargo, esto se hace más evidente sobre los despoblados municipios de la ruta 1. La excepción está en Tunja y Duitama que mantienen una mayor concentración de población. Paralelo a ello, la ruta 3 experimenta un menor proceso de despoblamiento.

Teniendo en cuenta la dificultad de evidenciar las dinámicas demográficas de los municipios pequeños en los mapas anteriores, puesto que frente a una población tan grande como la de Bogotá D.C., todos los demás rangos se ven muy disminuidos, se vio la necesidad de utilizar como variable la tasa de crecimiento intercensal, cuyos rangos se establecen en razón al tamaño de cada municipio y de esta forma es posible identificar la dinámica de crecimiento o decrecimiento de los pequeños ${ }^{6}$.

5 Esta información histórica de TPD para 1968, 1973, 1985, 1993 y 2005 fue recabada gracias al archivo personal del profesor Jorge Matiz, ingeniero de transporte.

6 Ejemplo, frente a un rango de población de 7 millones desaparecen los municipios de población menores, no así cuando se miran las tasas de crecimiento, pues un municipio puede tener 5.000 habitantes, pero si ganó 2.500 habitantes su tasa puede ser mayor que la del municipio que teniendo 7 millones aumenta 700.000. En el primer caso la tasa será del 50\% mientras que el segundo apenas llegaría al 10\%. 


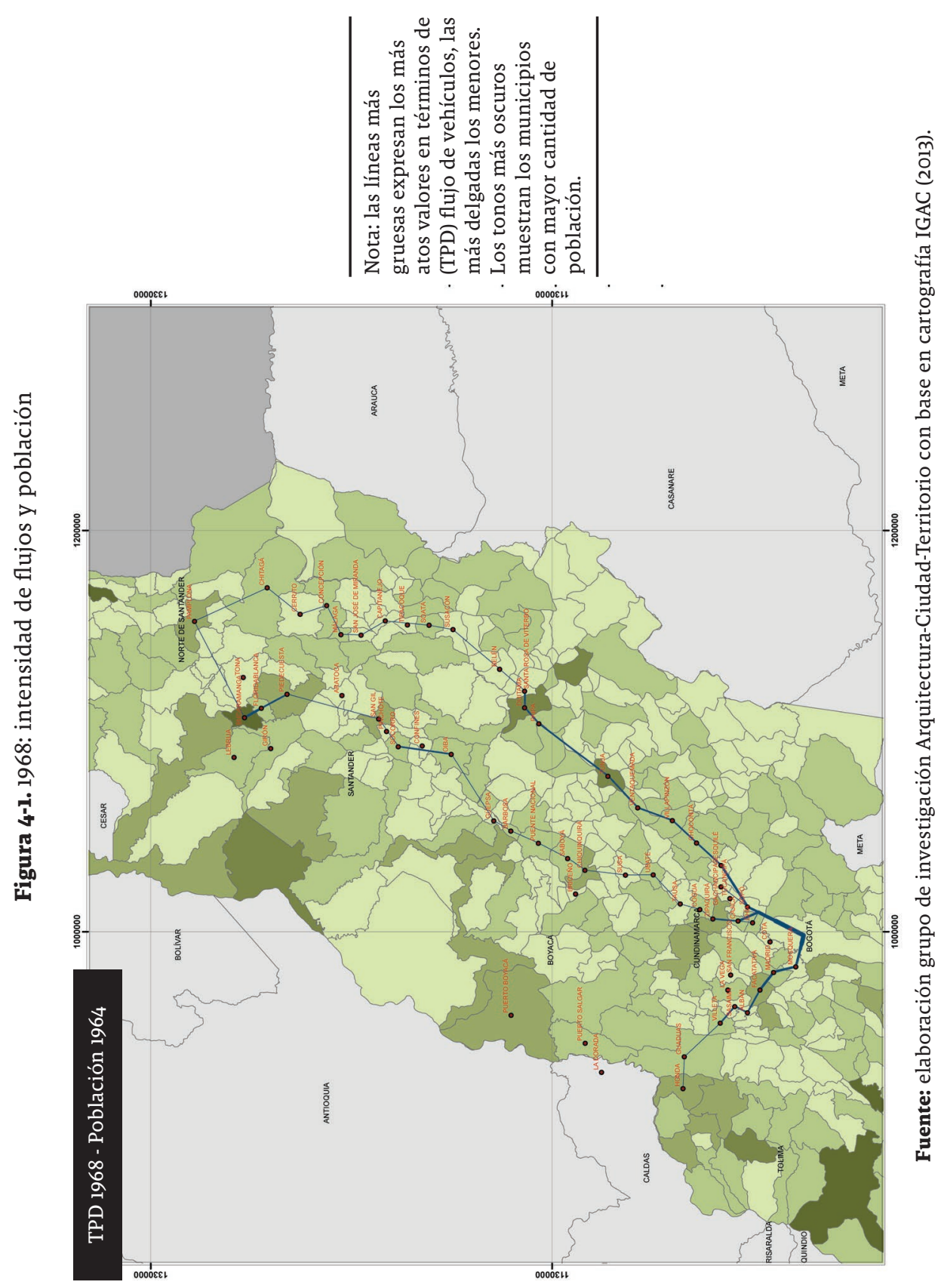



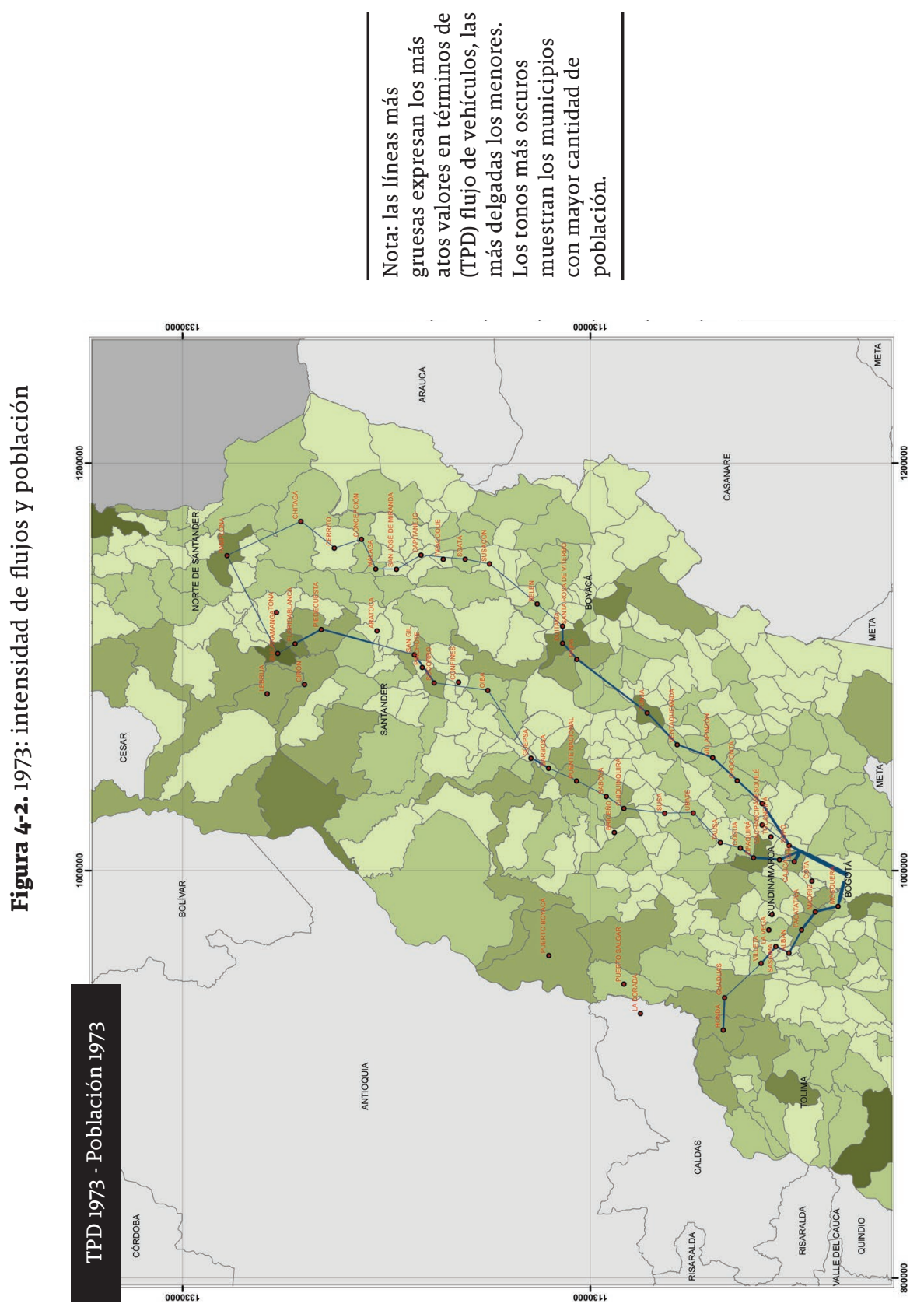

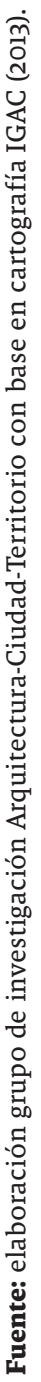




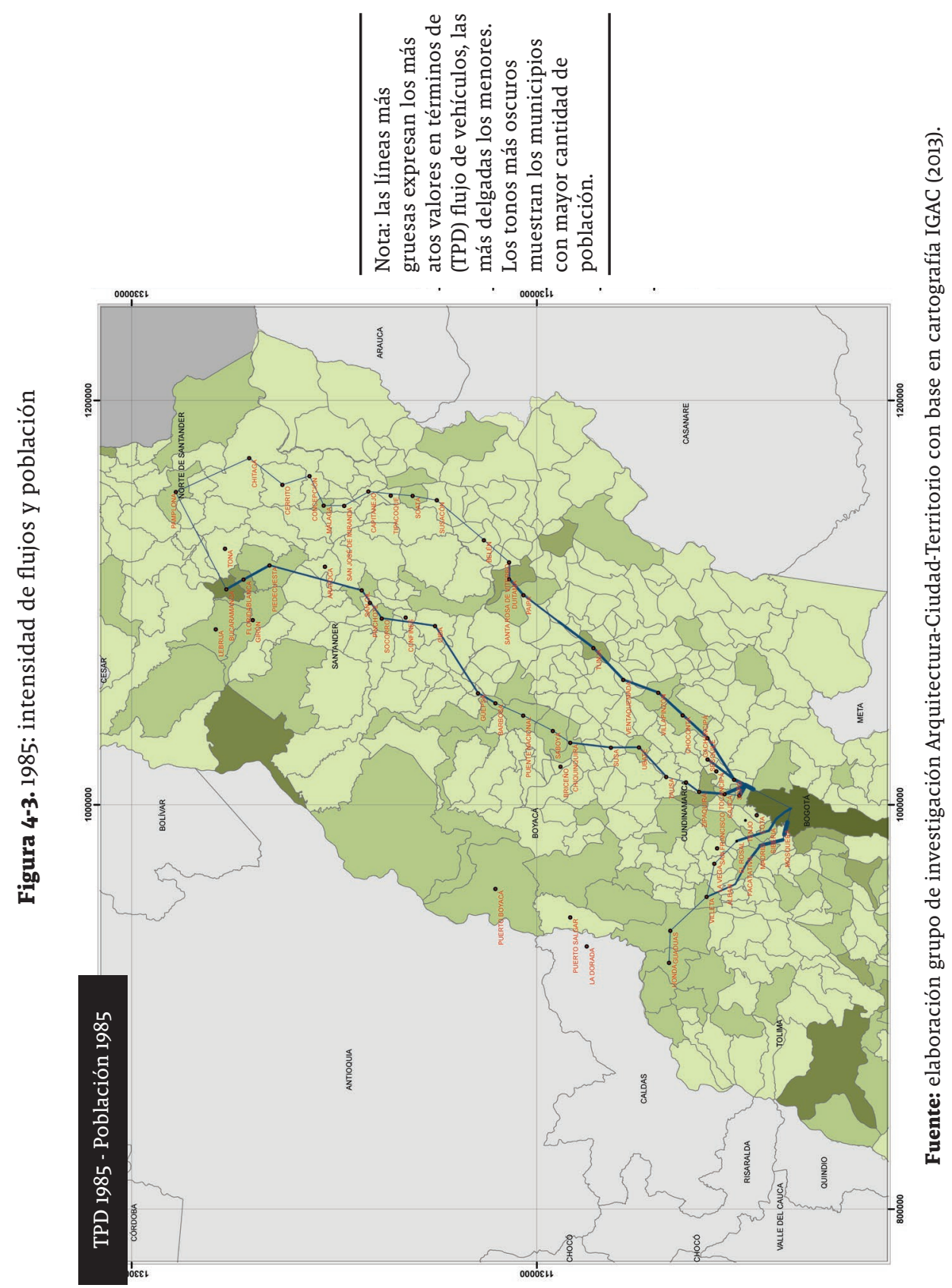




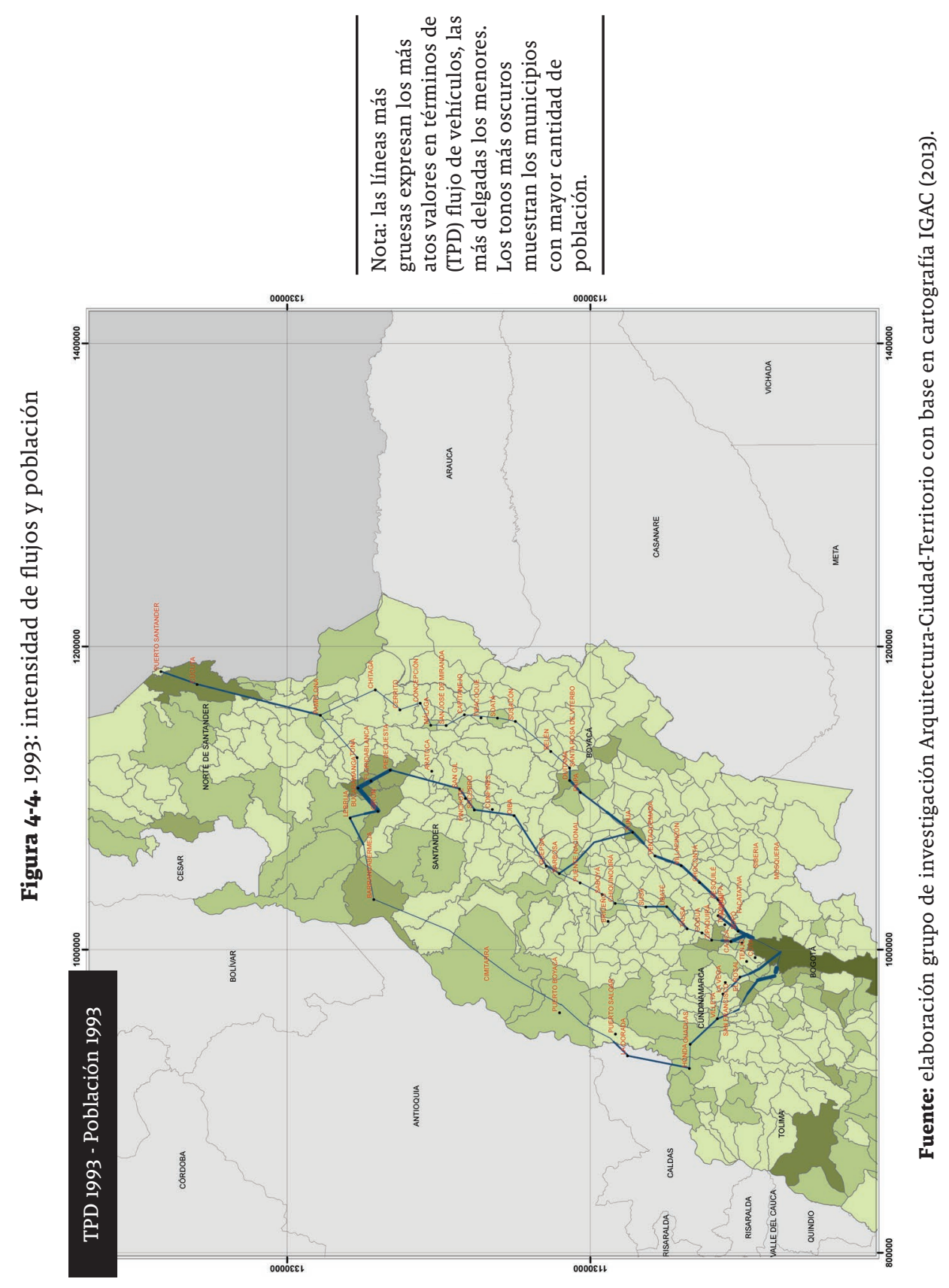




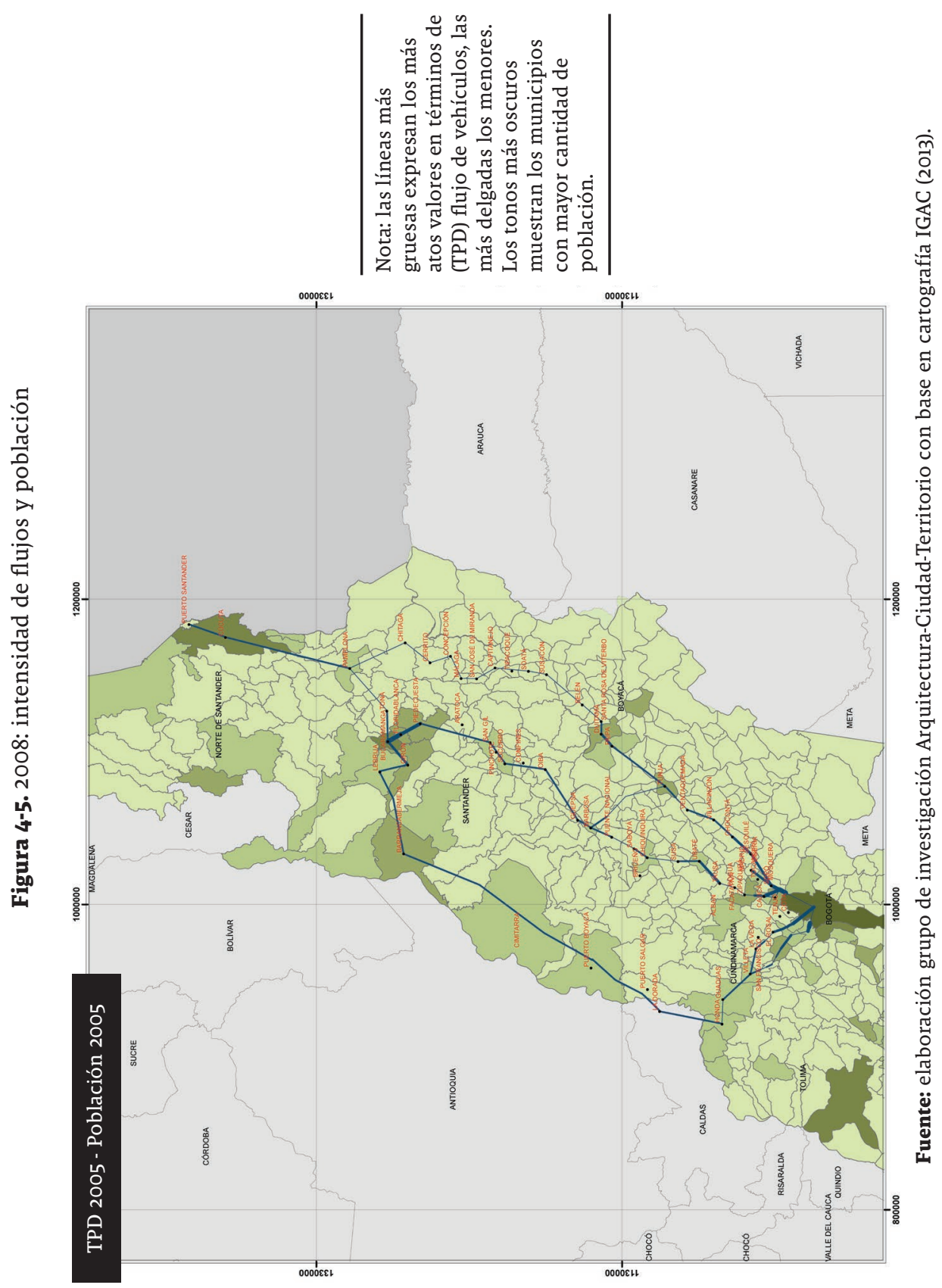


Manteniendo los datos de TPD para cada ruta, se incorpora la tasa de crecimiento para los municipios de los tres departamentos, encontrando algunos elementos coincidentes para cada período de tiempo analizado. Los resultados siguen destacando la estrecha relación entre caída de población y dinámica urbano-regional medida en términos de flujos de intercambio (ruta 1) y viceversa, aumento en las dinámicas demográficas y en los flujos de intercambio (figura 5-1 a 5-5).

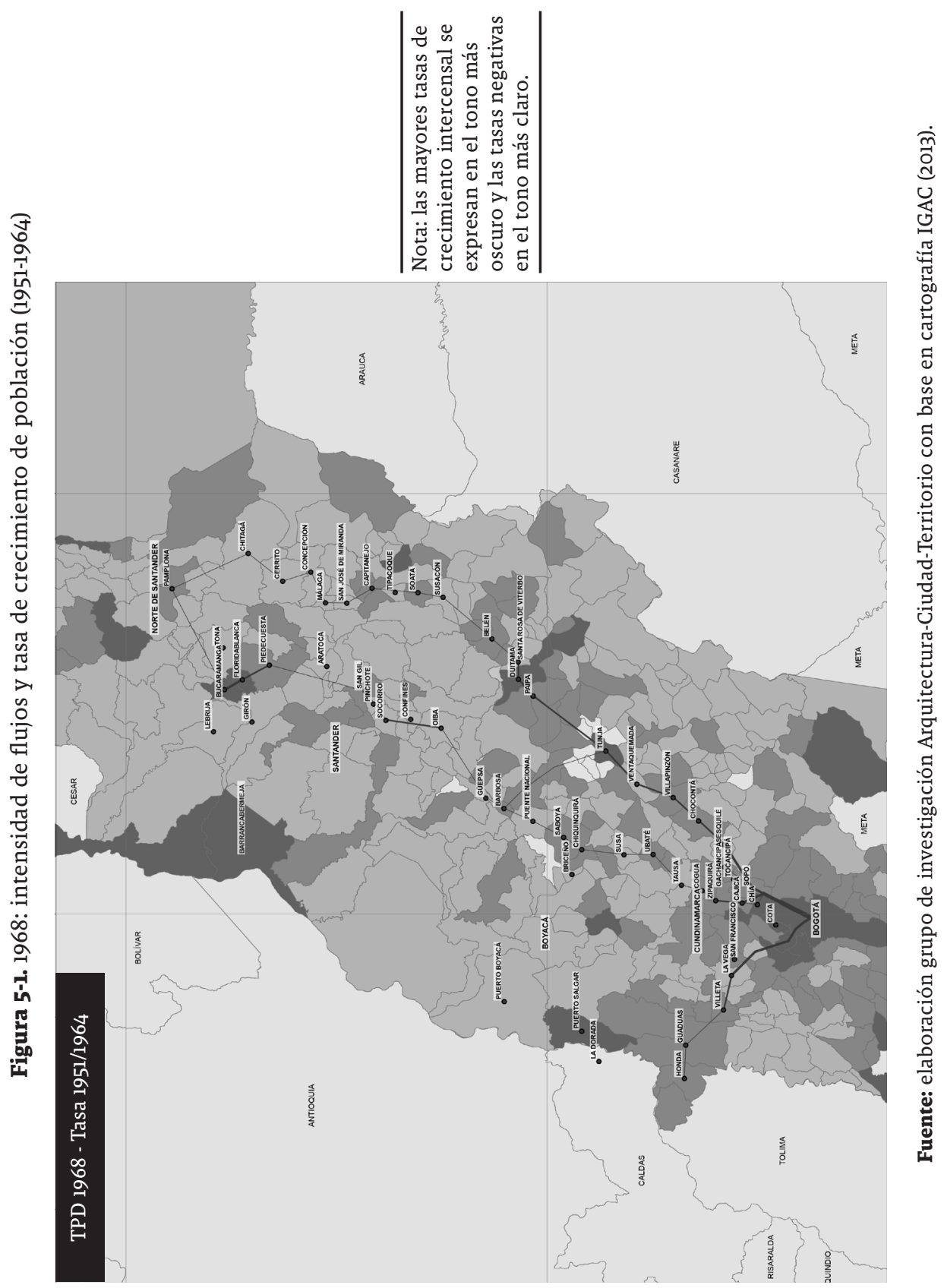




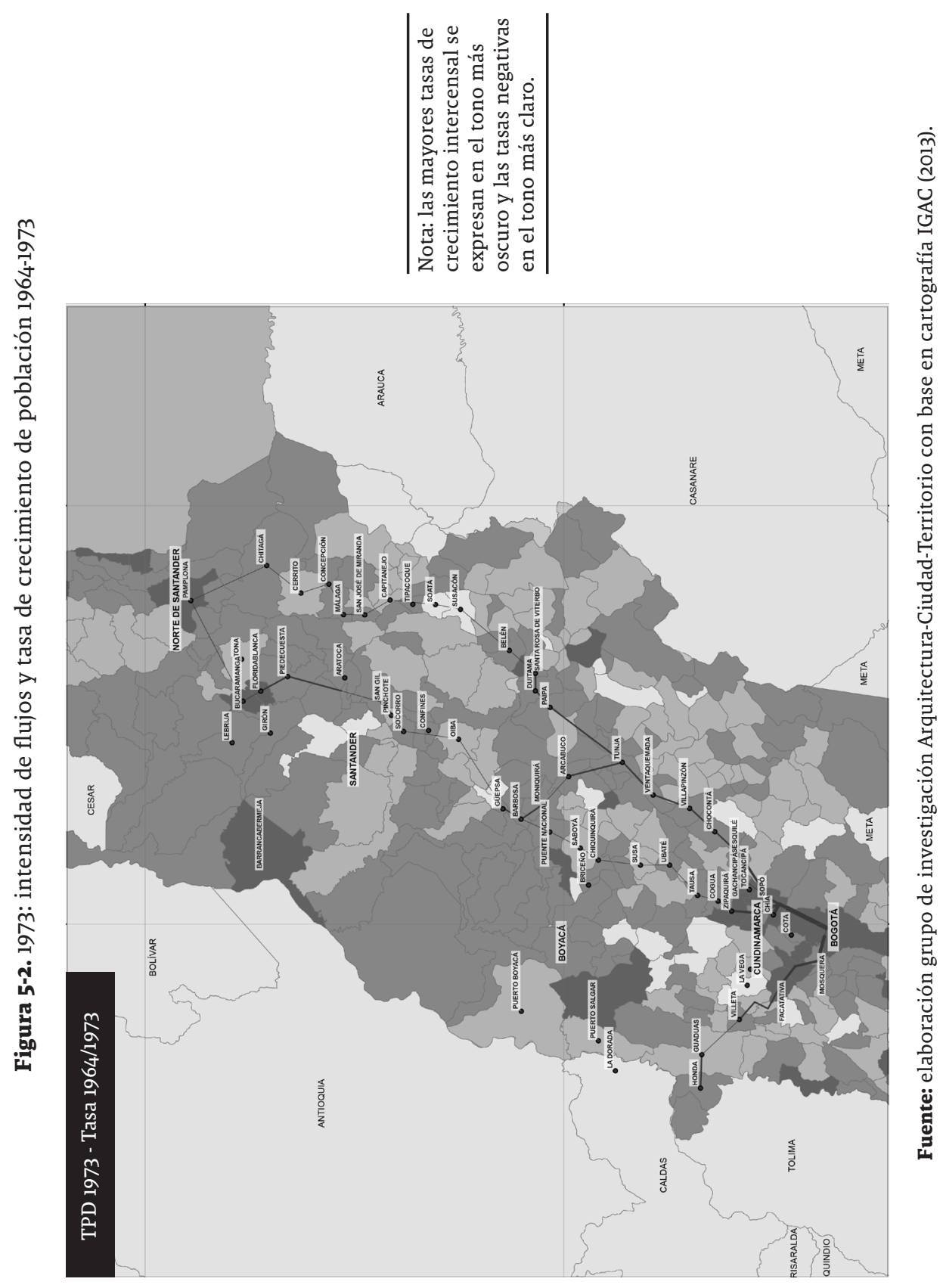




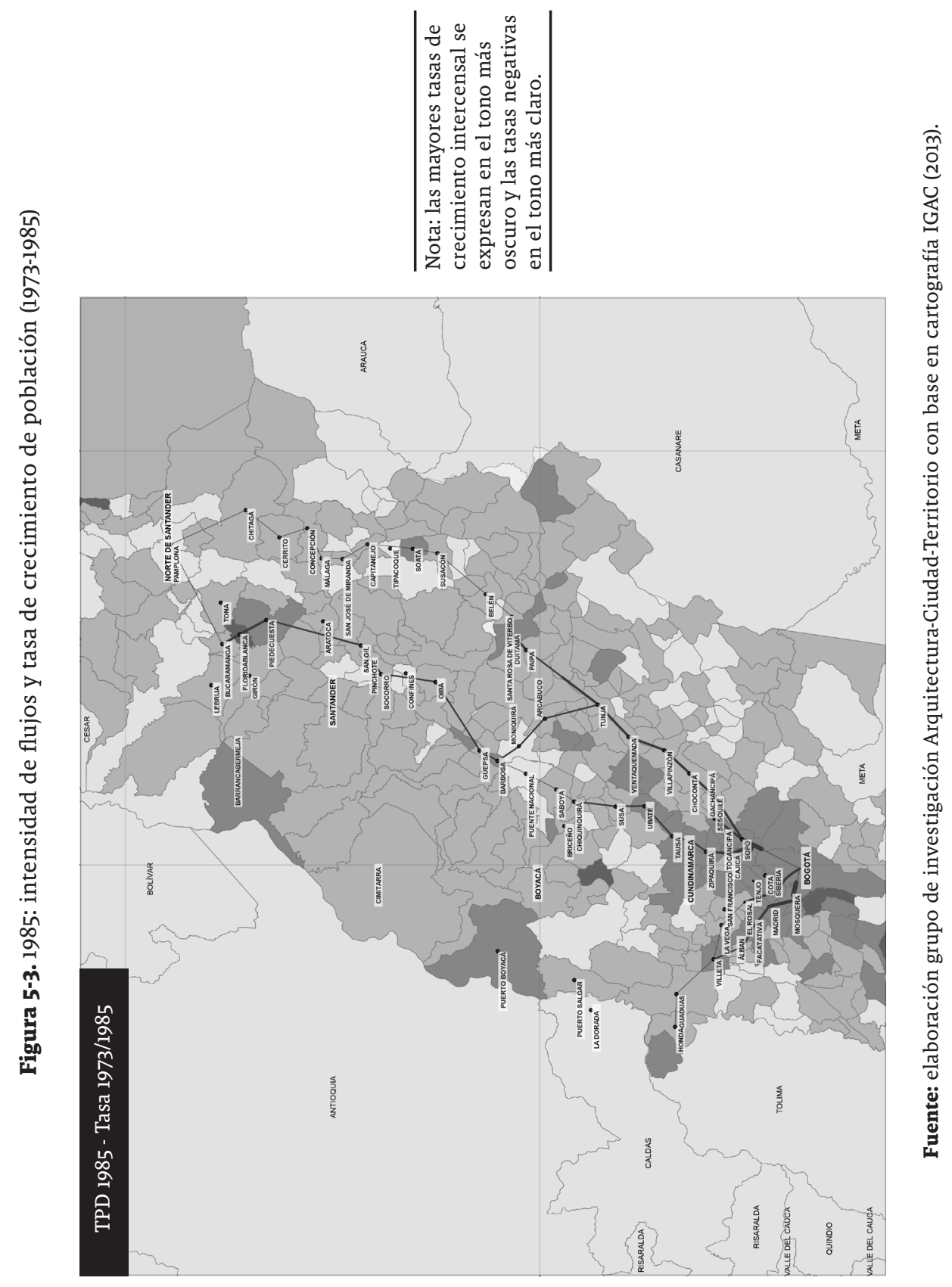




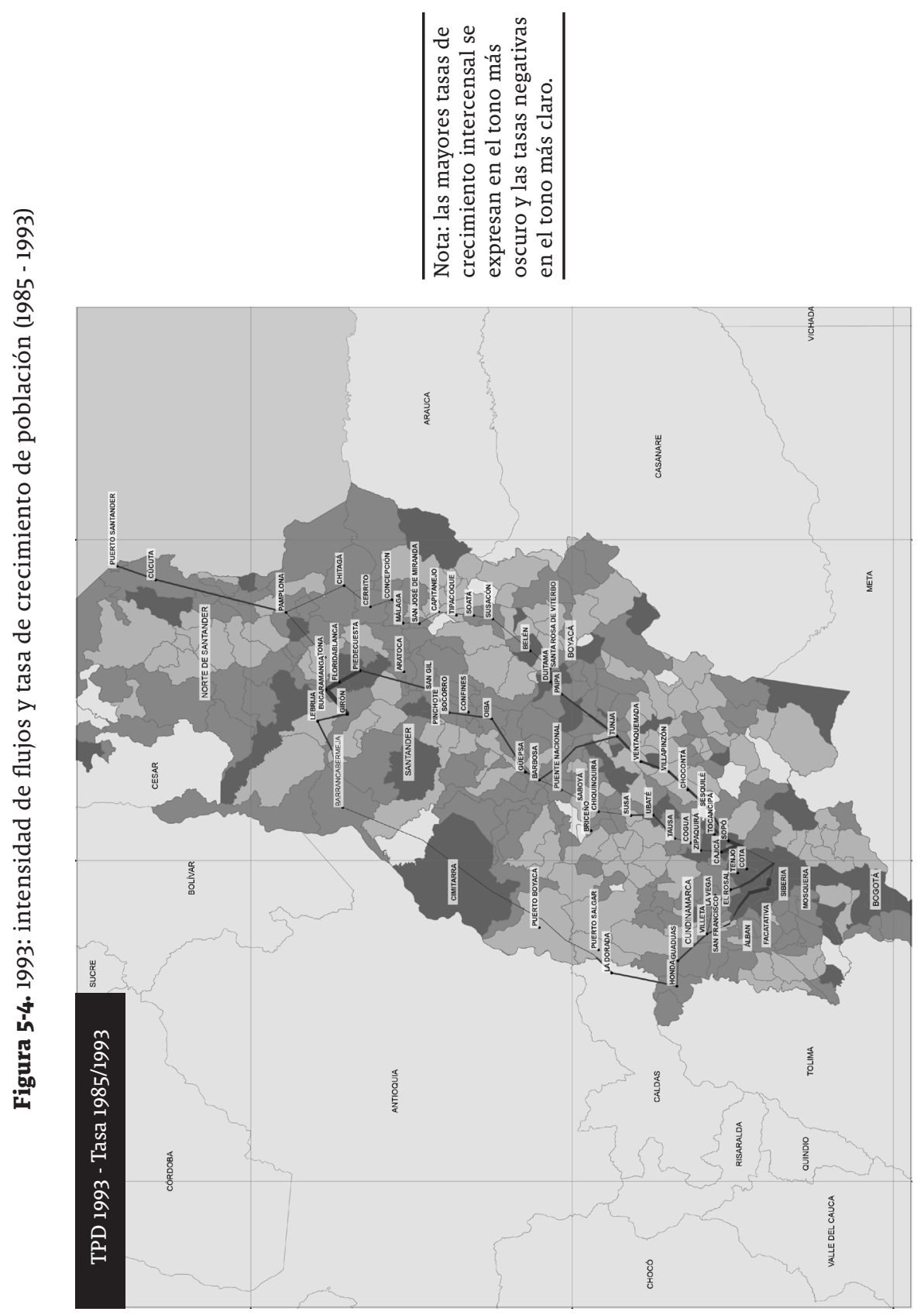

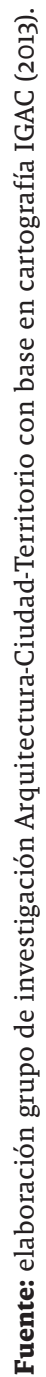




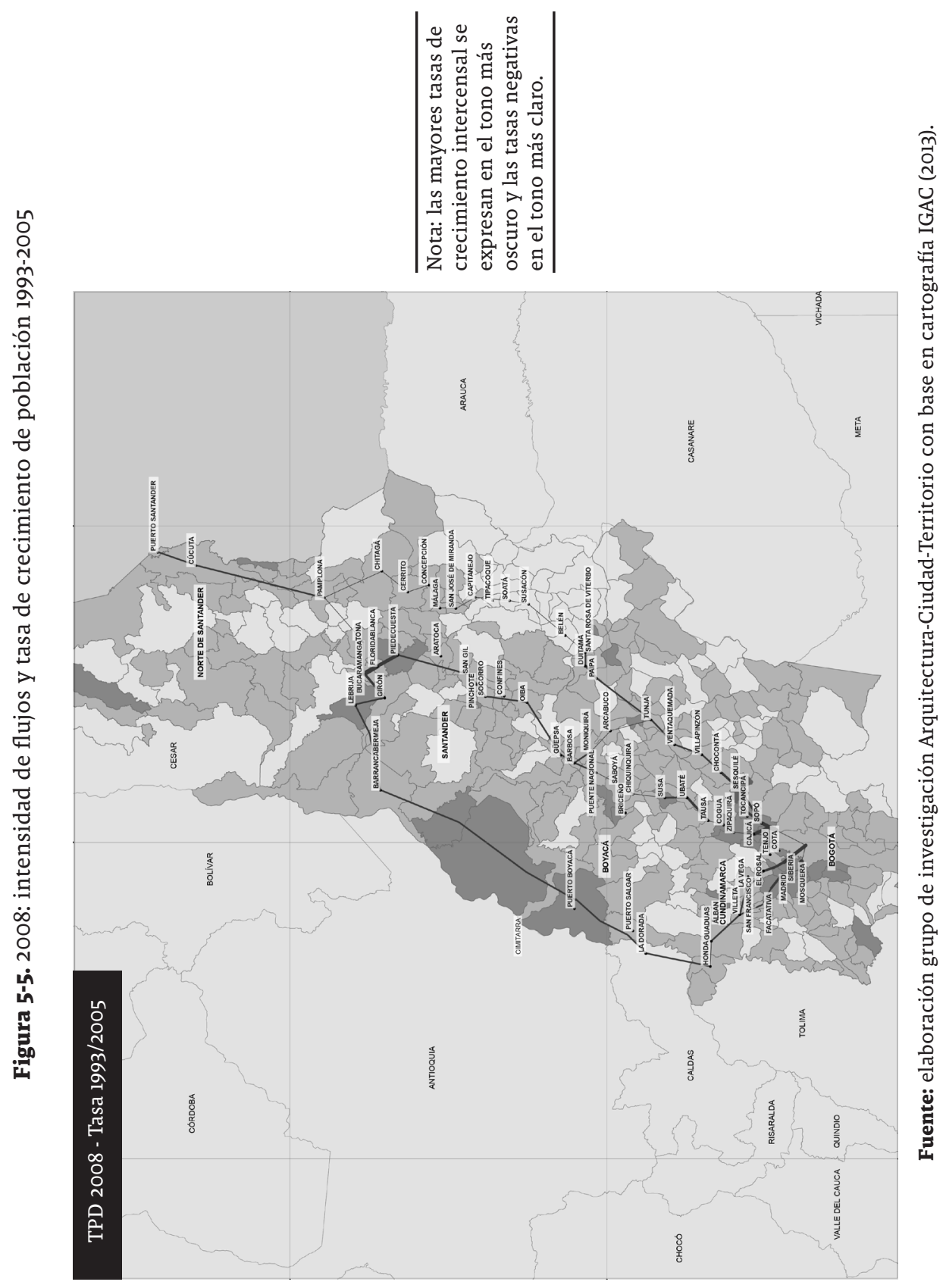




\section{b. Eficiencia de la red}

Tomando como referente el estudio de López, Mancebo y Ortega (2006) se ha tratado de acopiar la información para poder resolver la fórmula $(E=(\Sigma$ trij $/ \Sigma$ tiii). Wij) identificada en ese estudio, la cual mide el indicador de eficiencia de la red, en razón de la calidad de las infraestructuras disponibles y de la relación entre los tiempos de desplazamiento reales y los ideales entre dos puntos de una red?

$$
\mathrm{E}=\sum_{j} \frac{t r_{i j}}{t i_{i j}} \cdot w_{i j}
$$

Donde:

trij: tiempo real de viaje entre el origen y el destino

tiij: tiempo óptimo o ideal de viaje entre el origen y el destino

Wij: peso ponderado entre i y $j$.

Debido a las dificultades ocasionadas al tratar de conseguir información oficial y confiable sobre distancias y tiempos de recorrido entre los municipios ubicados sobre las tres rutas de estudio, necesaria para desarrollar la fórmula mencionada, se recurrió a las siguientes fuentes: 1) Instituto Nacional de Vías (Invías) para las distancias reales; 2) Información recabada sobre la ruta 1 y 2 en la salida de campo sobre los tiempos parciales entre distintos municipios de la vía; 3) información de empresas de buses para la ruta 3.

La fórmula desarrollada para cada una de las tres rutas se construyó uniéndolas tramo por tramo. Esto mostró que si bien cada nueva ruta presenta una relación mejor entre tiempo real y tiempo óptimo (gráfico l), también presenta tramos con mayor y menor eficiencia. Por ejemplo, la ruta 1 en su conjunto tiene los menores indicadores de eficiencia, pero en su recorrido los tramos entre Pamplona-Bucaramanga y Málaga-Pamplona afectan negativamente este indicador puesto que presenta la mayor distancia entre el tiempo real y el ideal. En la ruta 2, el tramo Chiquinquirá-Barbosa es el que mayor eficiencia aporta a la ruta 2, mientras que el tramo Barbosa-San Gil es el que hace más ineficiente en términos de tiempo esta ruta. En la ruta 3, el tramo Bogotá-Guaduas es el que mayor distancia presenta entre el tiempo ideal de desplazamiento y el tiempo real de desplazamiento. En este análisis se observa que al comparar los tramos que componen la ruta 3, el tramo que presenta mayor nivel de accesibilidad es el comprendido entre Honda y Puerto Boyacá.

\section{Resultados comparados del indicador de eficiencia entre las rutas 1, 2 y 3.}

Al comparar la eficiencia en tiempos de desplazamiento en las rutas 1, 2 y 3, es evidente que la ruta 3 es más eficiente que la 2 , y esta a su vez es más eficiente que la 1.

La ruta 1 , en cambio, muestra mayor ineficiencia debido a que es $38 \%$ más ineficiente en la accesibilidad Bogotá-Bucaramanga que la ruta 2.

Lo anterior parece mostrar que la eficiencia está ligada a recorrer una parte importante de la ruta en terreno plano y también a conectar la menor cantidad de

7 Indicador adimensional. 
Gráfico 1. Comparación del indicador de eficiencia para las tres rutas*

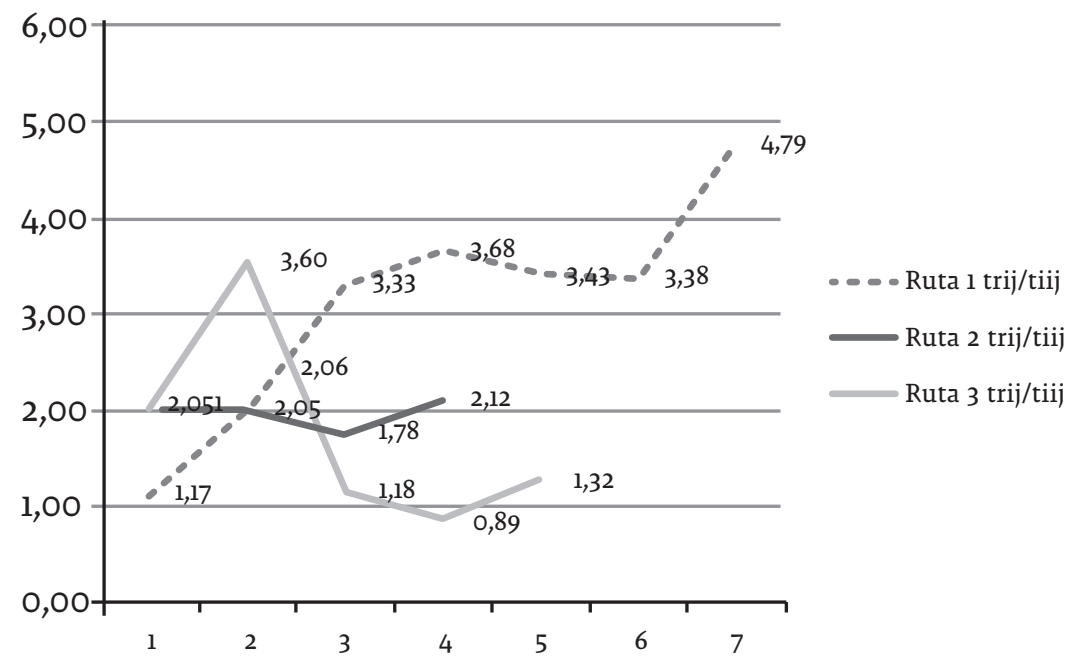

* Se debe recordar que este es un indicador adimensional, por tanto, las longitudes de las tres líneas correspondientes a las rutas 1, 2 y 3 no tienen relación con sus distancias reales en kilómetros, sino con la cantidad de puntos intermedios sobre los que se obtuvo información.

Fuente: elaboración grupo de investigación Arquitectura-Ciudad-Territorio.

municipios o zonas actualmente pobladas. Un interesante estudio a realizar pasada una década sería poder ver si el impacto de la ruta 3 por la zona menos poblada del Magdalena medio ha generado un cambio en sus municipios, si han cambiado sus jerarquías, si se han creado nuevos municipios o si siguen manteniéndose los mismos.

\section{c. Actividad agrícola}

Se quiso hacer una aproximación a otros indicadores de la variable económica. Sin embargo, las estadísticas oficiales producidas por el Ministerio de Agricultura, el Ministerio de Comercio y por el Banco de la República no están desagregadas por municipios 8 . En ocasiones se hace por renglones económicos en los ámbitos nacional o departamental, pero no municipal. Por esta razón, recurrimos a las más recientes cartografías sobre la economía del sector agrícola construidas por el DANE y desagregadas por municipios, y las contrastamos con lo observado durante la salida de campo realizada en el trascurso de la investigación. Revisando los diferentes productos agrícolas que allí se detallan en relación con los ejes viales del estudio, solamente pudimos establecer una relación entre los siguientes productos que abastecen la escala regional y cada una de las tres rutas (figura 6-1 a 6-3).

La ruta 1 que conecta buena parte del altiplano Cundiboyacense, situado en el centro del país, muestra una especialización en la producción de papa coincidente con los municipios donde los TPD muestran mayor flujo, mientras que la intensidad

8 Ya se había comentado en la introducción, que los investigadores de la red GaWC de Gran Bretaña se lamentaban de las dificultades para obtener información específica sobre ciudades de importancia global. 


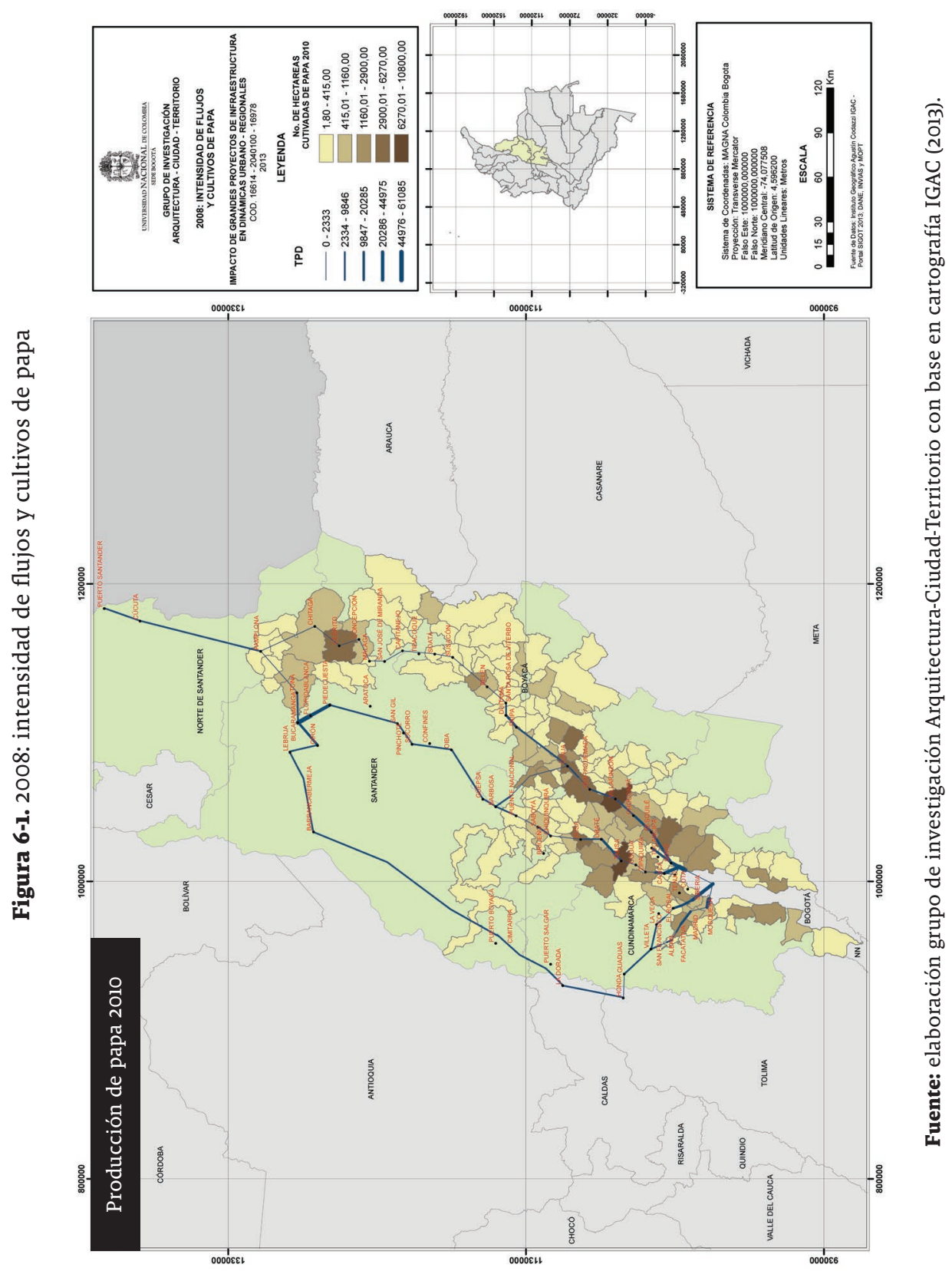




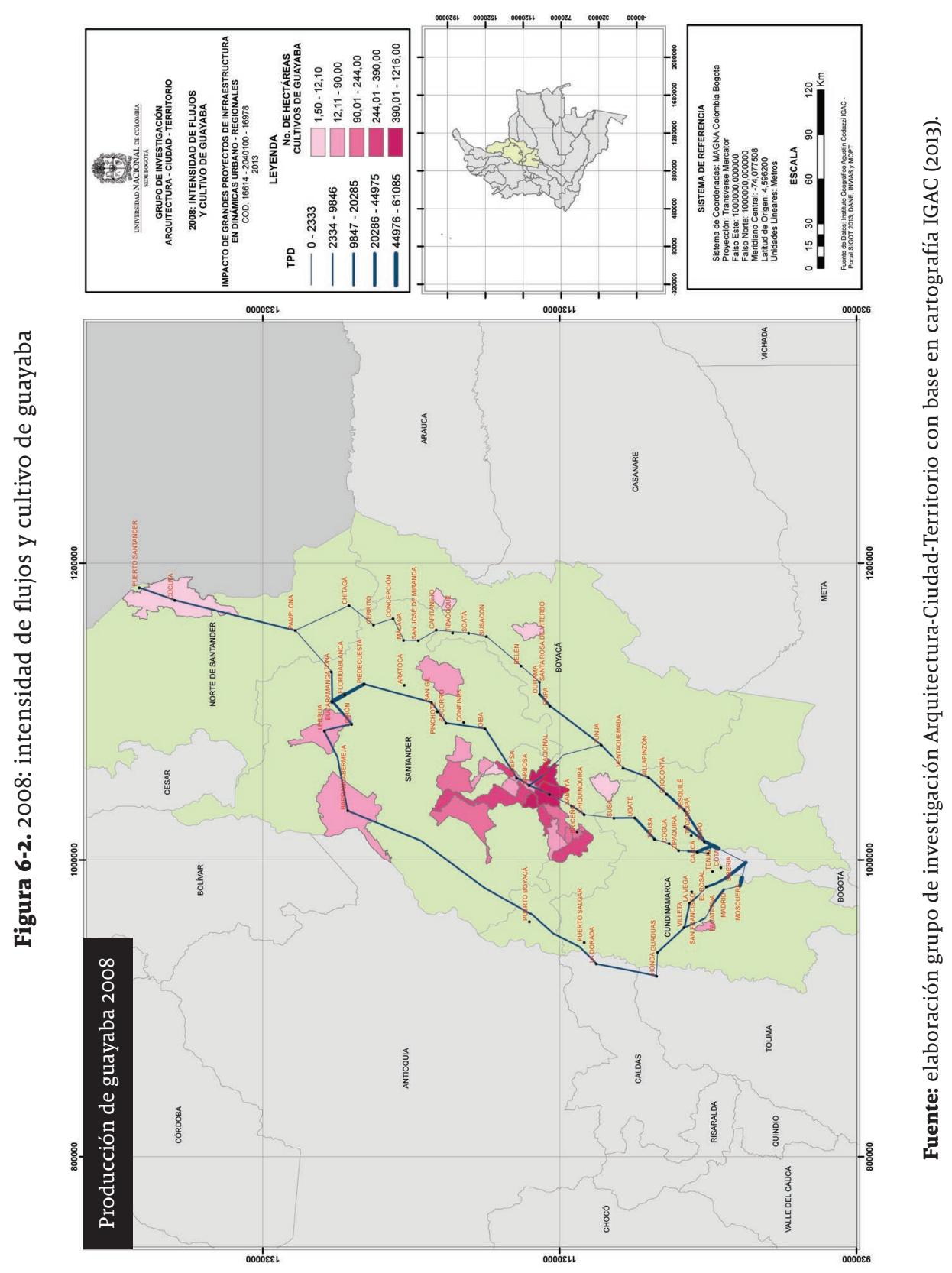




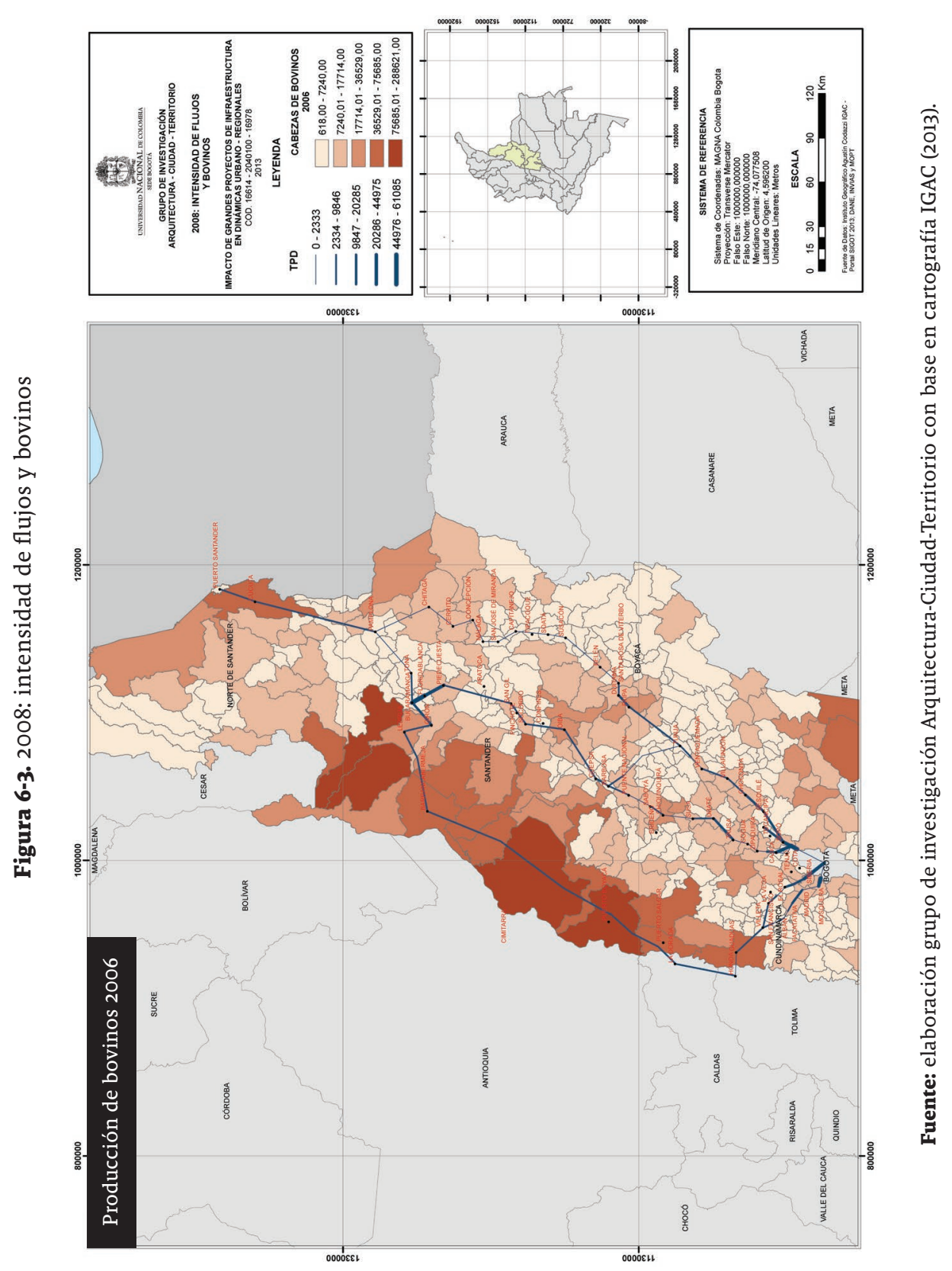


del tráfico es menor (tonos más suaves en el mapa) en los municipios donde este producto no es significativo. La ruta 2 permite hacer una relación en el entorno de municipios como Barbosa entre intensidad de flujos automotores y producción de guayaba. La ruta 3 muestra una relación mayor entre producción bovina e intensidad mayor de flujo automotor; mencionemos que los municipios del Magdalena Medio presentan un mayor predominio de propiedades latifundistas dedicadas a la ganadería. Sin pretender que esta información nos brinde una explicación definitiva sobre las dinámicas económicas asociadas al funcionamiento de cada una de las tres rutas, sí permite hacer unas primeras hipótesis sobre un cierto grado de especialización productiva en el sector agropecuario.

\section{Conclusiones}

En épocas anteriores la construcción de vías de comunicación estaba estrechamente ligada con los sitios o regiones donde se asentaba la mayor cantidad de personas y, en ese sentido, su principal objetivo era facilitar sus comunicaciones e intercambios de escala local o regional. Ahora, las nuevas rutas están más orientadas a atravesar de la forma más rápida posible un territorio, reduciendo las fricciones que su posible paso por poblaciones ocasionarían. Esto es posible de empezar a percibir con la ruta 3, especialmente donde transcurre paralela al río Magdalena, y no atraviesa ningún municipio.

Lo anterior explica por qué las vías anteriores comunicaban muchas más poblaciones que las actuales, como se pudo verificar que ocurre entre la ruta 1 y la 3 del estudio de caso. Se dejan abandonadas vías que comunican poblaciones que en algún período anterior fueron importantes regionalmente (ruta l) como se verificó mediante el indicador de eficiencia vial para el caso de estudio. Se dejan abandonadas poblaciones que presentan procesos de estancamiento, ocasionando una pérdida no solo a estos territorios sino al país en su conjunto que va quedando cada vez más fragmentado y desequilibrado. Una política de equilibrio territorial debería encaminarse a promover procesos de reconversión social y económica.

Asociado a los años de fundación y a la lectura de las divisiones municipales mostradas en las figuras 4 y 5 , vemos que el área de los municipios ubicados sobre la ruta más antigua (ruta l) es más pequeña que la de aquellos servidos por rutas más recientes, como es el caso de la ruta 3. Esta evidencia gráfica muestra los procesos de subdivisión que han ocurrido en el tiempo, muy seguramente producto de las luchas por el poder político y económico que se presentan en los municipios que en algún momento de su historia fueron muy dinámicos, lo que frecuentemente desemboca en la segregación de parte del territorio para constituir un nuevo municipio.

Lo anterior también permite visualizar los cambios de jerarquías que se producen dentro de una región. Algunos municipios disminuyen su jerarquía, como es el caso de los ubicados más al norte sobre la ruta l; aumentan su jerarquía, como algunos ubicados sobre la ruta 2; o aparece uno nuevo, como en la ruta 3 en la que -siendo la más reciente- aún están por verse nuevos efectos. En el caso de los departamentos también ocurre algo similar: Cundinamarca que inicia teniendo cinco municipios sobre la ruta 1 acaba teniendo siete en la ruta 
más nueva, mientras que Boyacá que inició con nueve municipios en la ruta más antigua no aparece con ninguno en la ruta 3.

Cada época ha privilegiado unas economías que resultan dinamizadoras de poblaciones y generadoras de flujos de intercambio y esto en nuestro caso de estudio ha estado asociado a un cierto tipo de vía. Economías locales y regionales asociadas a un intenso poblamiento de las partes altas de la Cordillera Oriental van de la mano de la importancia que tuvo la ruta 1 . Por su parte la necesidad de la ruta 2 adquiere fuerza de la mano del ascenso de Bucaramanga como nodo urbano aglutinador de nuevas economías asociadas en sus inicios al café. Posteriormente la actividad petrolera centrada en la ciudad de Barrancabermeja jalonará la idea planteada en los años de 1960 de construir la ruta del Magdalena Medio, pero será la urgencia de mejorar la salida y entrada de mercancías a los puertos asociada a la política de apertura económica, la que le dará su mayor impulso hacía finales de los años noventa del pasado siglo.

Podría afirmarse, finalmente, que el modelo de economía puesto en marcha por el gobierno de un país no solo muestra el tipo de bienes que allí se producen (elaborados industrialmente o extraídos de sus recursos naturales sin mayor valor agregado), sino que sus redes de comunicación estructuran de forma distinta el territorio. Bajo algunos modelos económicos se mantiene la prioridad de buscar una estructura equilibrada del territorio que facilite las comunicaciones y los intercambios entre sus habitantes y con los centros de producción. En otros, como puede ser el modelo de desarrollo económico neoliberal que predomina en el país, se deja de lado este aspecto y se privilegian las redes que lleguen hasta donde están las materias primas, sean estas agrícolas o mineras generándose así un continuo choque entre ordenamiento territorial -pensado en términos de equilibrio territorial- y apertura de nuevas vías de comunicación.

\section{Referencias bibliográficas}

DANE (Departamento Administrativo Nacional de Estadística). XV, XVI, XVII Censo Nacional de Población. Resultado oficial Censos de Población. Bogotá: Imprenta Nacional, 1951; 1964; 1973; 1985, 1993, 2005.

Díaz, Sonia. «Papel territorial de las infraestructuras de transporte». Paper presentado en Seminario Internacional "Territorios, Ordenamiento, Desarrollo", Bogotá, Colombia, 10 y 11 de octubre de 2012.

Espinosa, Miguel, Patricia Rincón y Teresa Ramírez. Construcción de la línea de investigación en dinámicas urbano-regionales. Bogotá: s.e., 2011.

Hissong, Robin. Las teorías y las prácticas de desarrollo desde la perspectiva de la modernidad. Bogotá: Universidad de Los Andes, 1996.

IGAC (Instituto Geográfico Agustín Codazzi). Cartografía base (Material cartográfico digital). Bogotá D.C.: IGAC, 2013.

Kanitscheider, Sigrun. "Transit Traffic in the Alps and the Andes. One Phenomenon, Different Perceptions». In Challenges for Mountain Regions Tackling Complexity, edited by Axel Boxdorf, Georg Grabherr, and Johann Stötter, 138-143. Viena: Böhlau, 2010. 
López, Elena, Emilio Ortega y Ana Condeço-Melhorado. «Análisis de impactos territoriales del plan estratégico de infraestructuras y transporte de infraestructuras y transporte 2005-2020: cohesión regional y efectos desbordamiento». Revista de Economía, no 848, 2009: 159-172.

López, Elena, Santiago Mancebo y Emilio Ortega. Evaluación de efectos territoriales: accesibilidad y medio ambiente debidos al PEIT en Castilla y León, 2006. http://www.ciccp.es/biblio_digital/Icitema_III/congreso/pdf/020503.pdf (último acceso: 15 de marzo de 2011).

Morin, Edgar. Introducción al pensamiento complejo. Barcelona: Gedisa, 1998.

Pachón, Álvaro y María Ramírez. La infraestructura de transporte en Colombia durante el siglo XX. Bogotá: Fondo de Cultura Económica, 2006.

Pereira de Brito, Eliseu. «La carretera Belén-Brasilia y la ocupación del territorio en el sudeste de la Amazonía legal, Brasil». Paper presentado en Seminario Internacional "Territorios, Ordenamiento, Desarrollo", Bogotá, Colombia, 10 y 11 de octubre de 2012.

Rincón, Patricia y Diana Sandoval. Línea de investigación en dinámicas urbano regionales. Propuesta de marco conceptual. Avance de investigación. Bogotá: s.e., 2012.

Taylor, Peter. «Hierarchical Tendencies amongst World Cities: A Global Research Proposal». GaWC Research Bulletin, ${ }^{\circ}{ }^{1}$, 1997. Available in http://www.lboro. ac.uk/gawc/rb/rbl.html (Accessed: 12 de marzo de 2011).

Zambrano, Fabio. Ciudad y territorio, el proceso de poblamiento en Colombia. Bogotá: Tercer Mundo, 1993. 